\title{
Toward standardized test methods to determine the effectiveness of filtration media against airborne nanoparticles
}

Journal Article

Author(s):

Wang, Jing; Tronville, Paolo

Publication date:

2014

Permanent link:

https://doi.org/10.3929/ethz-b-000084153

Rights / license:

In Copyright - Non-Commercial Use Permitted

Originally published in:

Journal of Nanoparticle Research 16(6), https://doi.org/10.1007/s11051-014-2417-z 


\title{
Toward standardized test methods to determine the effectiveness of filtration media against airborne nanoparticles
}

\author{
Jing Wang • Paolo Tronville
}

Received: 12 February 2014/Accepted: 11 April 2014/Published online: 7 May 2014

(C) Springer Science+Business Media Dordrecht 2014

\begin{abstract}
The filtration of airborne nanoparticles is an important control technique as the environmental, health, and safety impacts of nanomaterials grow. A review of the literature shows that significant progress has been made on airborne nanoparticle filtration in the academic field in the recent years. We summarize the filtration mechanisms of fibrous and membrane filters; the air flow resistance and filter media figure of merit are discussed. Our review focuses on the air filtration test methods and instrumentation necessary to implement them; recent experimental studies are summarized accordingly. Two methods using monodisperse and polydisperse challenging aerosols, respectively, are discussed in detail. Our survey shows that the commercial instruments are already available for generating a large amount of nanoparticles, sizing, and quantifying them accurately. The commercial self-contained filter test systems provide the possibility of measurement for particles down to $15 \mathrm{~nm}$.
\end{abstract}

J. Wang $(\bowtie)$

Institute of Environmental Engineering, ETH Zurich, 8093 Zurich, Switzerland

e-mail: jing.wang@ifu.baug.ethz.ch

J. Wang

Analytical Chemistry, EMPA (Swiss Federal Laboratories for Materials Science and Technology), 8600 Dübendorf, Switzerland

P. Tronville

Department of Energy, Politecnico di Torino, Corso Duca degli Abruzzi, 24, 10129 Turin, Italy
Current international standards dealing with efficiency test for filters and filter media focus on measurement of the minimum efficiency at the most penetrating particle size. The available knowledge and instruments provide a solid base for development of test methods to determine the effectiveness of filtration media against airborne nanoparticles down to singledigit nanometer range.

Keywords Airborne nanoparticle filtration . Standards · Test methods · Fibrous filters · Membrane filters · Instrumentation .

Environmental effects

\section{Introduction}

Aerosol filtration is used in diverse applications, such as air pollution control, emission reduction, respiratory protection for human, and processing of hazardous materials (Hinds 1999). The rising awareness of environmental agencies and the general public for a cleaner environment is forcing many industries to consider a filtration process in their plants. Another driving force is the growing necessity of a clean air environment in many advanced industries, such as electronics, medical, pharmaceuticals, biological research, gas turbine and nuclear energy installations, automotive applications (Tronville and Rivers 2005a, b), and others. 
The filtration of airborne nanoparticles is becoming an important issue as they are produced in large quantities from material synthesis and combustion emission. Nanoparticles, i.e., particles with at least one dimension under $100 \mathrm{~nm}$, have high mobility in airborne form. They may pose a serious health risk because of the high mobility and the increased toxicity due to the large specific surface area. Emitted into the environment, they may potentially lead to new hazards or increased risks to the environment (Oberdörster et al. 2005; Maynard and Pui 2007; Wang et al. 2011a).

Filtration has been extensively studied experimentally and theoretically; models for clean fibrous filter media are well developed and systematically documented by Brown (1993), Hinds (1999), and Lee and Mukund (2001). Filtration of nanoparticles, due to its emerging importance and impact on environment and health protection, has attracted voluminous research in recent years. Shaffer and Rengasamy (2009) reviewed respiratory protection against airborne nanoparticles and concluded that industrial hygienists and safety professionals should continue to use traditional respirator selection guidance for workers exposed to nanoparticles. Mostofi et al. (2010) reviewed the literature on the filtration performance of mechanical filters and respirators against nanoparticles. The review of Wang and Otani (2013) focused on fibrous filters and their performance against nanoparticles.

The process of air filtration is complicated, and although the general principles are well known there is still a gap between theory and experiments (Wang 2013). Questions exist regarding the filtration of nanoparticles down to single-digit nanometers because of possible thermal rebound; the electrostatic mechanism plays an important role for nanoparticle filtration and its modeling and quantification still need to be improved; the development of new filter media such as nanofiber filters deserves further studies and modeling efforts. Filtration testing for nanoparticles, especially those down to single-digit nanometers, is a challenging task which necessitates generation of a large amount of exceedingly small particles, and accurate sizing and quantification of such particles. Thus, state-of-the-art aerosol instruments are usually required and meticulous protocols are implemented to avoid artifacts and errors. Current international standards dealing with efficiency test for filters and filter media focus on measurement of the minimum efficiency at the most penetrating particle size (MPPS).
Further work is needed toward standardization of nanoparticle filtration.

We review the literature on filtration of airborne nanoparticles with a focus on the filtration test methods and instruments. First the filtration mechanisms are introduced. The pressure drop and figure of merit for filters are considered. Experimental studies are summarized with respect to the test methods and instruments, particle size range, and material and filter characteristics. The commercial available instruments which can be used in nanoparticle filtration systems are reviewed. Current standards relevant to nanoparticle filtration are summarized.

\section{Filtration mechanisms}

The aerosols carried by the air stream are removed in the filter due to different mechanisms. The fractional penetration $P$ represents the fraction of aerosols passing through the filter, defined as

$P=C_{\text {down }} / C_{\text {up }}$,

where $C_{\text {down }}$ and $C_{\text {up }}$ are the aerosol concentrations downstream and upstream of the filter, respectively. The filter efficiency $E$ is the fraction of aerosols removed by the filter,

$E=1-P$.

The parameters for the filtration conditions, including the face velocity, air viscosity, and temperature, have impact on the filtration efficiency. We consider the filtration mechanisms for both fibrous filters and membrane filters.

Filtration mechanisms for fibrous filters

Fibrous filter media are mats composed of fibers. In non-woven fibrous filters, the fibers are bonded together by entangling structures mechanically, thermally, or chemically. They are not made by weaving or knitting. The fiber orientations can be rather random, even though the fibers are oriented mainly perpendicular to the aerosol flow. The fiber sizes are often not uniform. Woven fabrics and mesh screens can also be modeled as fibrous filters. The single-fiber efficiency $E_{\Sigma}$, defined as the ratio of the number of particles collected by a fiber to the number of particles 
in the volume of air geometrically swept out by the fiber (Hinds 1999), is related to the filter penetration through

$P=\exp \left(\frac{-4 \alpha E_{\Sigma} t}{\pi(1-\alpha) d_{f}}\right)$,

where $t$ is the filter media thickness, $d_{\mathrm{f}}$ is the fiber diameter, and $\alpha$ is the filter solidity or the fraction of the solid material in a filter. The total single-fiber efficiency $E_{\Sigma}$ has contributions from different collection mechanisms and can be written as

$E_{\Sigma} \approx E_{\mathrm{D}}+E_{\mathrm{R}}+E_{\mathrm{DR}}+E_{\mathrm{I}}+E_{\mathrm{G}}+E_{\mathrm{E}}$,

where $E_{\mathrm{D}}, E_{\mathrm{R}}, E_{\mathrm{I}}, E_{\mathrm{G}}$, and $E_{\mathrm{E}}$ represent the collection efficiencies due to diffusion, interception, inertial impaction, gravity, and electrostatic effect, respectively; $E_{\mathrm{DR}}$ accounts for the enhanced collection due to interception of the diffusing particles.

The diffusion mechanism accounts for the particles undergoing Brownian motion which then hit the fibers and are captured. Diffusion can be the dominating mechanism for nanoparticle filtration. The dimensionless parameter, Peclet number $P e$, represents the relative importance of convection and diffusion and is defined as

$P e=\frac{d_{\mathrm{f}} U_{0}}{D}$, and

$D=\frac{k T C_{\mathrm{c}}}{3 \pi \mu d_{\mathrm{p}}}$,

where $U_{0}$ is the filtration face velocity, $\mu$ is the air dynamic viscosity, $D$ is the diffusion coefficient, $k$ is the Boltzmann constant, $T$ is the absolute temperature, $d_{\mathrm{p}}$ is the particle diameter, and $C_{\mathrm{c}}$ is the slip correction factor. The single-fiber efficiency due to diffusion is a function of $P e$ and different researchers gave somewhat different expressions based on theoretical derivation or empirical data (Stechkina 1966; Kirsch and Fuchs 1968; Cheng and Yeh 1980; Lee and Liu 1982; Wang et al. 2007). The analysis of Lee and Liu (1982) led to

$E_{\mathrm{D}}=2.58\left(\frac{1-\alpha}{K u}\right)^{1 / 3} P e^{-2 / 3}$,

which is valid for $0.05<\alpha<0.2,10^{-3}<U_{0}<2 \mathrm{~m} /$ s, and $0.1<d_{\mathrm{f}}<50 \mu \mathrm{m}$. $\mathrm{Ku}$ is the Kuwabara hydrodynamic factor which accounts for the effect by neighboring fibers on the flow around a fiber:
$K u=-0.5 \ln \alpha-0.75-0.25 \alpha^{2}+\alpha$.

The interception effect is due to the finite size of the particles under the assumption that the particles follow the air flow streamlines. Interception occurs when the particle center comes within one particle radius of the fiber surface. The single-fiber efficiency due to interception can be determined from the air flow around the fiber and the particle size. With the Kuwabara flow field, the interception efficiency can be expressed as (Lee and Liu 1982)

$$
\begin{aligned}
E_{\mathrm{R}}= & \frac{1+R}{2 K u}\left[2 \ln (1+R)-1+\alpha+\left(\frac{1}{1+R}\right)^{2}\left(1-\frac{\alpha}{2}\right)\right. \\
& \left.-\frac{\alpha}{2}(1+R)^{2}\right]
\end{aligned}
$$

and

$R=d_{\mathrm{p}} / d_{\mathrm{f}}$.

Interception may play an important role for nanoparticle filtration, especially when the fiber size is small.

Inertial impaction occurs when the particle inertia keeps it from following the abruptly changing streamlines near the fiber, thus the particle hits the fiber. The Stokes' number Stk characterizes the inertia of the particle and is defined as

Stk $=\frac{\rho_{\mathrm{p}} d_{\mathrm{p}}^{2} C_{\mathrm{c}} U_{0}}{18 \mu d_{\mathrm{f}}}$,

where $\rho_{\mathrm{p}}$ is the particle density. When the Stokes' number is high, the particle is moving almost in a straight line with its initial velocity. The drag force on the particle can be approximated by that acting on the particle moving in a straight line, and then the movement of the particle can be obtained. Brown (1993) used this perturbation approach and obtained the following expression for the efficiency due to inertial impaction $E_{\mathrm{I}}$ at high Stokes' numbers

$E_{\mathrm{I}}=1-\chi / \mathrm{Stk}$,

where $\chi$ is a constant depending on the flow field. It appears that Brown's equation was obtained by considering the particle as a point mass (Wang and Pui 2009).

When the interception efficiency is finite and the Stokes' number is small, the single-fiber efficiency can be computed based on the assumption that the particle trajectory deviates slightly from the gas streamline. 
Stechkina et al. (1969) gave the following expression for particles with low Stokes' numbers

$$
\begin{aligned}
E_{\mathrm{I}}= & \frac{1}{(2 K u)^{2}}\left[\left(29.6-28 \alpha^{0.62}\right) R^{2}-27.5 R^{2.8}\right] \\
& \text { Stk for } R<0.4 .
\end{aligned}
$$

Brown (1993) summarized results for inertial impaction from calculations and experiments. The values of the efficiency due to inertial impaction spread out in rather wide ranges at small Stokes' numbers (Figs. 4.5-4.10 in Brown 1993). It appears that accurate determination of the inertial impaction efficiency at small Stokes' numbers is still difficult, possibly due to the difficulty in indentifying contributions from different filtration mechanisms in this range. Hinds (1999) stated that in estimating the overall single-fiber collection efficiency near the size of minimum efficiency, it is necessary to include an interaction term to account for enhanced collection due to interception of the diffusing particles:

$E_{\mathrm{DR}}=\frac{1.24 R^{2 / 3}}{(K u P e)^{1 / 2}}$.

At the normal filtration velocities (on the order of $\mathrm{cm} /$ $\mathrm{s}$ and tens of $\mathrm{cm} / \mathrm{s}$ ), inertial impaction is not expected to be an important mechanism for nanoparticles. However, inertial fibrous filters have been developed for sampling and collecting nanoparticles at face velocities up to $50 \mathrm{~m} / \mathrm{s}$ (Otani et al. 2007; Furuuchi et al. 2010). The results showed that inertial impaction was the dominant capture mechanism at higher velocities.

Gravitational settling may lead particles to deviate from the streamlines and to be collected in the filter, which is typically only important for particles above a few micrometers and at low face velocities. Usually it is negligible for nanoparticles.

The mechanisms due to diffusion, interception, inertial impaction, and gravity are known as mechanical capture mechanisms. When the aerosols or the filter possess electrostatic charges, or when the filter is subject to an external electrical field, the electrostatic capture mechanism is at play. Coulombic forces attract charged particles to oppositely charged fibers. A charged fiber can induce a dipole, or charge separation in a neutral particle. The particle is subject to the non-uniform electrical field generated by the fiber, thus the attractive force due to the separated charge on the near side of the particle is greater than the repulsive force on the far side. The result is a dielectrophoretic force which attracts the particle to the fiber. Similarly, a charged particle can induce an equal and opposite charge near the surface of a neutral fiber at close range. The resultant image force causes attraction between the particle and fiber; though the image forces are weaker than coulombic forces.

The charge level on the filter media fibers may change with time and usage, and application of external electrical field may overcome the decaying charge level problem. The external field can polarize a fiber and the resultant uniform field around the fiber can move a charged particle toward the fiber. Polarization of particles by the externally field also can produce dielectrophoretic forces on them.

The electret filters, with intentionally electrically charged fibers, take advantage of the electrostatic attraction to improve the filtration efficiency, without affecting the flow resistance. Brown (1993) discussed the effect of charge amount and configuration on filtration. The greater the amount of charge on the filter media fibers, the greater will be the electrical field, and the higher the filtration efficiency by electrostatic attraction. Charge configuration is also important. Uniform charge distribution is not of great value in filtration, because the field between two fibers carrying the same charge may be low, and the field outside of the filter may cause dielectric breakdown of air, thus limiting the charge that the filter could hold. To be effective in air filtration, the electrical field must extend a significant distance beyond the surface of a charged fiber. Hence, the electrical charge must have a spatial variation not much smaller than fiber or inter-fiber dimensions.

Brown (1993) analyzed the single-fiber efficiency for fibers with uniform charge distributions and twodimensional charge distributions. In the case of a fiber carrying a uniform charge $Q$ per unit length, the nondimensional parameter governing the capture due to coulombic force is

$N_{Q q}=\frac{Q q C_{\mathrm{c}}}{3 \pi^{2} \varepsilon_{0} \mu d_{\mathrm{p}} d_{\mathrm{f}} U_{0}}$,

where $q$ is the electrical charge on the particle and $\varepsilon_{0}$ is the vacuum permittivity. $N_{Q q}$ represents the ratio between the drift velocity of the particle due to coulombic force and the face velocity. Brown (1993) derived the following expression for single-fiber efficiency due to coulombic force by a uniformly 
charged fiber

$E_{Q q}=\pi N_{Q q}$.

Capture of neutral particles due to dielectrophoretic force by a uniformly charged fiber is governed by the parameter

$N_{Q 0}=\frac{Q^{2} d_{\mathrm{p}}^{2} C_{\mathrm{c}}}{3 \pi^{2} \varepsilon_{0} \mu d_{\mathrm{f}}^{3} U_{0}}\left(\frac{\varepsilon_{\mathrm{p}}-1}{\varepsilon_{\mathrm{p}}+2}\right)$,

where $\varepsilon_{\mathrm{p}}$ is the dielectric constant of the particle. When the dielectric force field is approximated by a solenoidal field with the same value at the fiber surface, the single-fiber efficiency for neutral particles due to dielectrophoretic force is approximately (Natanson 1957; Brown 1993)

$E_{Q 0}=\pi N_{Q 0}$.

Brown (1993) pointed out that Eq. 18 is applicable when $E_{Q 0}$ is small; when $E_{Q 0}$ is large, the efficiency can be approximated as (Kraemer and Johnstone 1955)

$E_{Q 0}=\left(\frac{3 \pi N_{Q 0}}{2}\right)^{1 / 3}$.

Stenhouse (1974) gave power law relationships between $E_{Q 0}$ and $N_{Q 0}$ by fitting numerical calculation results.

For fiber carrying non-uniform charges, the electrical field can be determined by the Poisson's equation. Brown $(1981,1993)$ gave solutions for the electrical field of a fiber carrying a line multipole charge. The dimensionless parameters for the capture due to coulombic force and dielectrophoretic force by the multipole charged fiber are, respectively,

$N_{\sigma q}=\frac{\sigma q C_{\mathrm{c}}}{3 \pi \varepsilon_{0}\left(1+\varepsilon_{\mathrm{f}}\right) \mu d_{\mathrm{p}} U_{0}}$,

$N_{\sigma 0}=\frac{2 \sigma^{2} d_{\mathrm{p}}^{2} C_{\mathrm{c}}}{3 \varepsilon_{0}\left(1+\varepsilon_{\mathrm{f}}\right)^{2} \mu d_{\mathrm{f}} U_{0}}\left(\frac{\varepsilon_{\mathrm{p}}-1}{\varepsilon_{\mathrm{p}}+2}\right)$,

where $\sigma$ represents the surface charge density and $\varepsilon_{\mathrm{f}}$ is the dielectric constant of the fiber. The surface density is equal to $\sigma$ multiplying the cosine of an integral product of the angular coordinate of the fiber surface. The dielectric constant of the fiber $\varepsilon_{\mathrm{f}}$ appears due to the internal electrical field in the fiber caused by the nonuniform charge distribution, which is not the case for a fiber carrying a uniform charge.
Brown (1981, 1993) and Pich et al. (1987) calculated capture of charged and neutral particles by multipole charged fibers. The efficiency depends on the orientation of the fiber, i.e., whether the particles approach the attractive or repulsive face of the fiber. If the distribution of the orientations is assumed to be random, an average may be taken. Power law relationships between the dimensionless parameters $N_{\sigma q}$ and $N_{\sigma 0}$ and the corresponding single-fiber efficiencies were given. Lathrache and Fissan (1989) also calculated the single-fiber efficiencies due to electrostatic attraction in the Kuwabara flow field and fitted them to formulas.

Brown (1981) analyzed the combined effect of electrostatic forces with interception and found that there exists a critical value of interception parameter, $R_{\mathrm{c}}$, below which interception does not affect the particle capture. Pich et al. (1987) calculated the combined single-fiber efficiency due to coulombic forces and interception; however, their expression did not take into consideration the existence of $R_{\mathrm{c}}$. Otani et al. (1993) compared the results of the above two studies and proposed expressions for the efficiency due to the combined effect of electrostatic forces with interception for a fiber with randomly distributed orientations of line dipole. Their expressions took different forms depending on the ranges of $N_{\sigma q}$ and $N_{\sigma 0}$ and whether the interception parameter is below the critical value.

Filtration mechanisms for membrane filters

The membrane filters generally possess higher solid fractions than fibrous filters and rely more on the surface filtration than on the depth filtration for particles larger than the rated pore sizes in the membrane (Rubow and Liu 1986; Liu et al. 2011). The filtration mechanisms for conventional solvent-cast membranes are similar to fibrous filters and the fibrous filter model was found to work well (Rubow 1981; Rubow and Liu 1986). Good agreement was found between the effective fiber diameter used in the model and the diameter of the fiber-like structures in solvent-cast membranes (Rubow and Liu 1986; Liu et al. 2011).

Nuclepore filters represent another type of membrane filters, which possess microscopic holes of uniform diameter, approximately perpendicular to the filter surface. The capillary tube model has been 
shown to accurately predict the particle collection characteristics of Nuclepore filters (Spurny et al. 1969; Manton 1978, 1979; Marre and Palmeri 2001; Cyrs et al. 2010; Chen et al. 2013a, b). Four filtration mechanisms have been considered for the Nuclepore membrane filters: impaction on the filter surface, interception on the pore opening, diffusion on the walls of the filter pore, and diffusion on the filter front surface. The four mechanisms are illustrated in Fig. 1.

The theoretical efficiency of impaction $\varepsilon_{i}$ is calculated as (Pich 1964)

$\begin{aligned} \varepsilon_{i} & =\frac{2 \varepsilon_{i}^{\prime}}{1+\xi}-\frac{\varepsilon_{i}^{\prime 2}}{(1+\xi)^{2}} \quad \text { with } \\ & \varepsilon_{i}^{\prime}=2 \operatorname{Stk} \sqrt{\xi}+2 \operatorname{Stk}^{2} \xi \exp \left[\frac{-1}{\operatorname{Stk} \sqrt{\xi}}\right]-2 \operatorname{Stk}^{2} \xi\end{aligned}$

Stk $=\frac{d_{\mathrm{p}}^{2} \rho_{\mathrm{p}} C_{\mathrm{c}} U_{0}}{18 \mu r_{0}} \quad$ and $\quad \xi=\frac{\sqrt{\phi}}{1-\sqrt{\phi}}$,

where $\phi$ : filter porosity, and $r_{0}$ : pore radius. The interception efficiency on pore opening $\varepsilon_{R}$ (Spurny et al. 1969) can be expressed as

$\varepsilon_{\mathrm{R}}=N_{\mathrm{R}}\left(2-N_{\mathrm{R}}\right) \quad$ with $\quad N_{\mathrm{R}}=d_{\mathrm{p}} /\left(2 r_{0}\right)$.

The diffusion efficiency in pore walls $\varepsilon_{\mathrm{D}}$ (Spurny et al. 1969; Twomey 1962) can be calculated as

\section{Fluid streamlines}

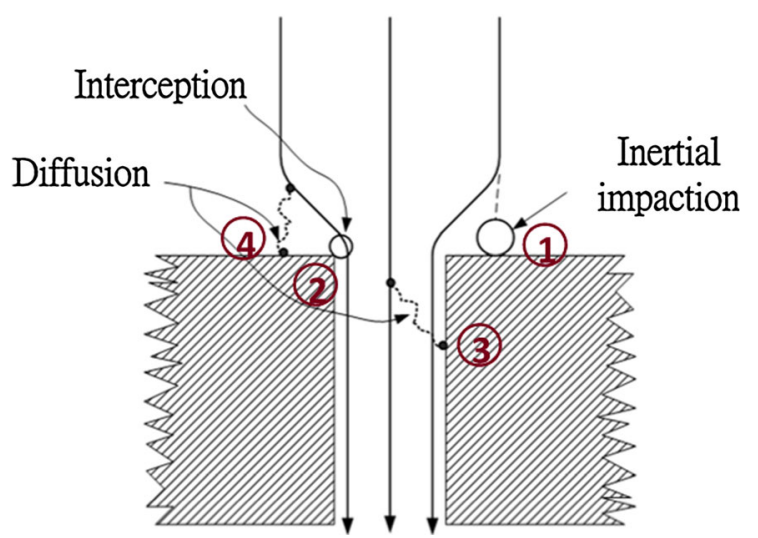

Fig. 1 Illustration of the four filtration mechanisms of a Nuclepore filter

$$
\begin{aligned}
\varepsilon_{\mathrm{D}} & =2.56 N_{\mathrm{D}}^{2 / 3}-1.2 N_{\mathrm{D}}-0.177 N_{\mathrm{D}}^{4 / 3} \text { for } N_{\mathrm{D}}<0.01 \text { or } \\
\varepsilon_{\mathrm{D}} & =1-0.819 \exp \left(-3.657 N_{\mathrm{D}}\right) \\
& -0.098 \exp \left(-22.305 N_{\mathrm{D}}\right)-0.032 \exp \left(-56.95 N_{\mathrm{D}}\right) \\
& -0.016 \exp \left(-107.6 N_{\mathrm{D}}\right) \quad \text { for } N_{\mathrm{D}}>0.01
\end{aligned}
$$

where $N_{\mathrm{D}}=\frac{t \phi D}{r_{0}^{2} U_{0}}$ represents the ratio between the diffusion displacement and the pore size. The efficiency of diffusion deposition on the front surface of the filter $\varepsilon_{\mathrm{DS}}$ may be expressed as (Manton 1979)

$\varepsilon_{\mathrm{DS}}=1-\exp \left\{\frac{-\alpha_{1} \Psi^{2 / 3}}{\left[1+\left(\alpha_{1} / \alpha_{2}\right) \Psi^{7 / 15}\right]}\right\}$,

where $\alpha_{1}=4.57-6.46 \phi+4.58 \phi^{2}, \alpha_{2}=4.5$, and $\Psi=\frac{D \phi^{1 / 2}}{r_{0} U_{0}}$.

The total filtration efficiency $\varepsilon_{\mathrm{T}}$ due to the above four mechanisms is then

$\varepsilon_{T}=1-\left(1-\varepsilon_{\mathrm{i}}\right)\left(1-\varepsilon_{\mathrm{R}}\right)\left(1-\varepsilon_{\mathrm{D}}\right)\left(1-\varepsilon_{\mathrm{DS}}\right)$.

Most penetrating particle size and minimum efficiency

Different capture mechanisms have different dependences on the particle size. Interception and inertial impaction become more effective when the size increases, diffusion becomes more effective when the size decreases, and electrostatic mechanism depends on particle size through mobility and charge distribution. As a consequence, there exists an intermediate particle size range where the particle penetration is maximum and the filtration efficiency is minimum. The corresponding particle size is termed the MPPS. The most penetrating size depends on the filtration parameters such as the face velocity, air viscosity, and temperature; filter parameters such as thickness, solidity, and fiber diameter; particle density; and electrical charge.

The MPPS is often in the range from 100 to $300 \mathrm{~nm}$ when only the mechanical capture mechanisms are at play, the fiber size is in micrometer to tens of micrometer range, the face velocity is on the order 


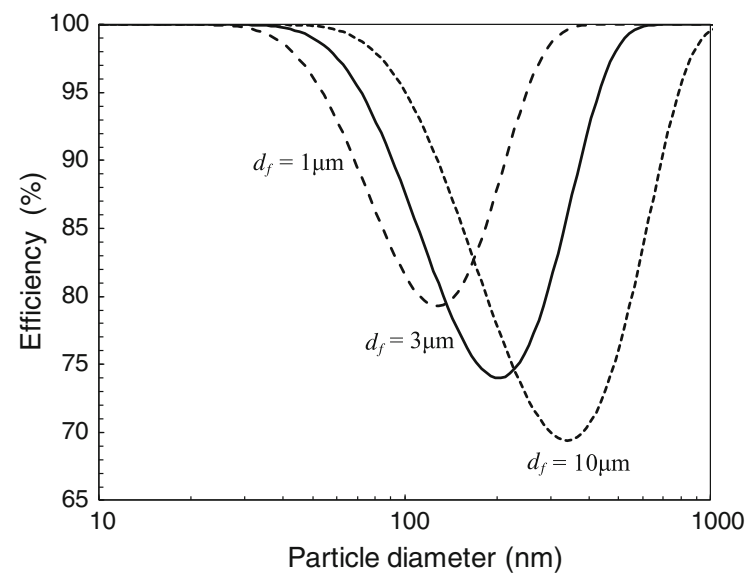

Fig. 2 The effect of fiber size $\left(d_{\mathrm{f}}\right)$ on filter efficiency as a function of particle size; $\alpha=0.05$ and $U_{0}=0.2 \mathrm{~m} / \mathrm{s}$. Filter thickness has been adjusted so that all three filters have the same pressure drop, as calculated by Eq. 36

of a few $\mathrm{cm} / \mathrm{s}$ or tens of $\mathrm{cm} / \mathrm{s}$, and the air is at normal temperature and pressure. This is the basis for using a dioctyl phthalate (DOP) synthetic aerosol having a mass size distribution with the mean size at $0.3 \mu \mathrm{m}$ for testing high-efficiency particulate air (HEPA) filters (Lee and Mukund 2001). It should be noted that the mean of the same size distribution if expressed in terms of number of particles would be shifted to a smaller size. Lee and Liu (1980) derived Eqs. 28 and 29 to predict the MPPS $d_{\mathrm{p}, \mathrm{min}}$, and the minimum single-fiber efficiency $E_{\min }$,

$d_{p, \text { min }}=0.885\left[\left(\frac{K u}{1-\alpha}\right)\left(\frac{\sqrt{\lambda} k T}{\mu}\right)\left(\frac{d_{\mathrm{f}}^{2}}{U_{0}}\right)\right]^{2 / 9}$,
$E_{\min }=1.44\left[\left(\frac{1-\alpha}{K u}\right)^{5}\left(\frac{\sqrt{\lambda} k T}{\mu}\right)^{4}\left(\frac{1}{U_{0}^{4} d_{\mathrm{f}}^{10}}\right)\right]^{1 / 9}$,

where $\lambda$ is the mean free path of air molecules. The derivation was based on the assumption that the only important mechanisms near the minimum efficiency are interception and diffusion. As the fiber size decreases, the MPPS decreases and the minimum efficiency becomes greater. These trends are illustrated in Fig. 2, in which the filter media efficiency is plotted as a function of the particle size for three fiber sizes.

\section{Pressure drop and filter figure of merit}

The pressure drop across the filter is an important consideration in filtration applications. For Nuclepore filters, the pressure drop $\Delta p$ can be computed using different expressions dependent on the pore Knudsen number

$K n_{\mathrm{p}}=\lambda / r_{0}$.

When $K n_{\mathrm{p}}<<1$, the flow is in the viscous regime and the pressure drop may be calculated by the Hagen-Poiseuille equation in the form (Spurny et al. 1969)

$\Delta p=p_{1}-p_{1} \sqrt{1-5.093 \frac{\mu t U_{0}}{p_{1} r_{0}^{4} N_{\mathrm{p}}}}$,

where $p_{1}$ is the gas pressure upstream of the filter and $N_{\mathrm{p}}$ is the number of pores per unit surface area. When $K n_{\mathrm{p}}$ is larger but still $K n_{\mathrm{p}}<1$, the slip effect should be considered because the air velocity at the pore wall is at finite values instead of zero. Then the pressure drop can be expressed as (Zaviska 1951; Spurny et al. 1969)

$\Delta p=p_{1}-p_{1} \sqrt{1-5.093 \frac{\mu t U_{0}}{p_{1} r_{0}^{4} N_{\mathrm{p}}\left(1+5.50 \lambda / r_{0}\right)}}$.

When $K n_{\mathrm{p}}$ is near unity or $>1$, the following equation can be used (Adzumi 1937; Spurny et al. 1969)

$$
\begin{aligned}
\Delta p= & p_{1}+3.42 \frac{\Omega \mu}{r_{0}} \sqrt{\frac{2 \pi R^{\prime} T}{M}} \\
& -\sqrt{\left[p_{1}+3.42 \frac{\Omega \mu}{r_{0}} \sqrt{\frac{2 \pi R^{\prime} T}{M}}\right]^{2}-5.093 \frac{\mu t p_{1} U_{0}}{r_{0}^{4} N_{\mathrm{p}}}}
\end{aligned}
$$

where $R^{\prime}$ is the universal gas constant, $M$ is the molecular weight of gas, and $\Omega$ is the Adzumi's constant. Spurny et al. (1969) used 0.75 for $\Omega$.

For fibrous filters, the pressure drop $\Delta p$ is related to the drag force per unit length $F_{\mathrm{d}}$ on individual fibers in fibrous filters by the following expression

$\Delta p=F_{\mathrm{d}} \frac{4 \alpha}{\pi d_{\mathrm{f}}^{2}} t$. 
The drag force in the Kuwabara flow is $F_{\mathrm{d}}=4 \pi \mu U_{0} /$ $K u$. If we assume that all the fibers have the same size and are distributed perpendicular to the flow and evenly, the pressure drop becomes

$\Delta p=\frac{16 \alpha}{K u \cdot d_{\mathrm{f}}^{2}} \mu U_{0} t$.

The linear relationship between the pressure drop and the media face velocity is in accordance with the Darcy's law when the flow is in laminar regime. For actual fibrous filter, the polydisperse fiber sizes, random orientations, and inhomogeneity make the pressure drop deviate from the above theoretical derivation. Davies (1973) gave an empirical expression for the pressure drop $\Delta p$

$$
\begin{aligned}
& \Delta p=\mu U_{0} t f(\alpha) / d_{\mathrm{f}}^{2} \quad \text { with } f(\alpha)=64 \alpha^{1.5}\left(1+56 \alpha^{3}\right) \\
& \quad \text { for } 0.006<\alpha<0.3 .
\end{aligned}
$$

It can be seen that the dependence of $\Delta p$ on $\mu, U_{0}$, and $t$ is the same in (35) and (36). They also show that $\Delta p$ is inversely proportional to $d_{\mathrm{f}}^{2}$. If $t, U_{0}$, and $\alpha$ are kept constant, then $\Delta p$ increases greatly when the fiber diameter changes from micrometers to nanometers. However, the pressure drop increase is lessened by the slip effect when the fiber size decreases, which can be characterized by the fiber Knudsen number

$K n=2 \lambda / d_{\mathrm{f}}$.

The larger the Knudsen number, the bigger the slip effects. The pressure drop based on the Kuwabara flow with slip effect can be computed as (Brown 1993, Eq. 3.65)

$$
\Delta p=\frac{16 \alpha(1+1.996 K n)}{d_{\mathrm{f}}^{2}\left[K u+1.996 K n\left(-0.5 \ln \alpha-0.25+\alpha^{2} / 4\right)\right]} \mu U_{0} t .
$$

To evaluate the overall performance considering both the penetration $P$ and pressure drop $\Delta p$, a useful criterion is the figure of merit $Q_{\mathrm{f}}$ (also known as the quality factor) which can be defined as

$Q_{\mathrm{f}}=-\ln (P) / \Delta p$.

Since $-\ln (P)$ provides a measure of the filter media efficiency, the figure of merit represents the ratio between the efficiency and the pressure drop $\Delta p$. Good filter media provide high efficiency and low pressure drop, thus larger values of $Q_{\mathrm{f}}$ indicate better filter media. In different applications, the relevant importance of the filter efficiency and pressure drop may be weighed differently. Thus there exist different ways to evaluate the overall filter performance.

\section{Nano-filtration experimental studies}

In the recent years, significant amount of experimental studies of filtration for nanoparticles has appeared in the literature. Otani et al. (1995) investigated removal of nanoparticles from air by stainless steel wire meshes, and observed thermal rebound for particles $<1 \mathrm{~nm}$. Ichitsubo et al. (1996) measured penetration of nanoparticles and ion clusters through stainless steel wire screens, and observed rebound for particles and ion clusters $<2 \mathrm{~nm}$. Alonso et al. (1997) questioned the sizing accuracy in the above two studies, and argued that a single differential mobility analyzer (DMA) may not provide accurate enough size measurement around $2 \mathrm{~nm}$ and below. Heim et al. (2006) also challenged Ichitsubo et al., attributing their findings to inaccurate particle size measurement of particles below 2-3 nm caused by an artifact of DMA diffusional broadening. Kim et al. (2006) measured the efficiency of a glass fiber filter media against particles down to $1 \mathrm{~nm}$ with the help of a particle size magnifier (PSM) for detection; rebound was observed for particles $<2 \mathrm{~nm}$.

In contrast, a number of studies of nanoparticles down to 2-3 nm reported no thermal rebound. Alonso et al. (1997) measured penetration of nanoparticles through wire screens and laminar flow tubes. To improve the sizing accuracy, they use a tandem DMA to determine the challenging particle size and no rebound effect was observed for particles down to $2 \mathrm{~nm}$ and for 1.36-nm ions. Heim et al. (2005) measured the filtration efficiency for particles below $20 \mathrm{~nm}$ through nickel screens and Heim et al. (2010) obtained the filtration efficiency for particles down to $1.2 \mathrm{~nm}$; no rebound was observed. Japuntich et al. (2007) compared two filter test methodologies for nanoparticles. Kim et al. (2007) and Wang et al. (2007) investigated penetration down to $3 \mathrm{~nm}$ through a variety of filter media, including screen filters, standard fiberglass filters, and a selection of personal protective equipment filters, and reported no rebound effect. Shin et al. (2008) measured filtration efficiency 
for silver nanoparticles and did not detect rebound for $3 \mathrm{~nm}$ particles at temperatures up to $500 \mathrm{~K}$. Mouret et al. (2011) tested penetration of copper nanoparticles in grids, and found no rebound effect for particles down to $4 \mathrm{~nm}$. Thomas et al. (2013) investigated penetration of charged and neutral aerosols through stainless steel and dielectric meshes. They found that the penetration for stainless steel mesh obeyed diffusion theory in the range $4-80 \mathrm{~nm}$. Thermal rebound is dependent on the material properties and more information than the particle size is needed to better understand it.

Protection against nanoparticles by respirators has been widely studied. Martin and Moyer (2000) studied the filtration efficiency of electrostatic respirator filter media for particles down to nanometer range. Balazy et al. (2006a, b) investigated the efficiency of respirators and masks against nanoparticles and viruses. They observed MPPS in diameter range of $\sim 30-70 \mathrm{~nm}$, due to the electrostatic effect. Some respirators may not provide the certified efficiency at the MPPS because they were certified at larger particle sizes. Rengasamy et al. (2007, 2008, 2009) studied performance of different types of respirators with focus on whether the filters provided expected levels of filtration protection against nanoparticles. They observed MPPS in the range of $30-60 \mathrm{~nm}$ and found that the tested filters provided expected level of protection. Eninger et al. (2008a, b) evaluated performance of respirators against viruses and ultrafine particles. Lee et al. (2008) obtained the protection factors for respirators and masks from human subject evaluation. Eshbaugh et al. (2009) measured respirator filter efficiency under high constant and cyclic flows. Golanski et al. (2009) studied protection against nanoparticles by fibrous filter media, masks, protective clothing, and gloves.

Boskovic et al. $(2005,2007,2008)$ measured the filtration efficiency for different nanoparticles and evaluated the particle shape effect. They found that the filtration efficiency was lower for cubic particles because of higher bouncing probability. Kim et al. (2009) investigated the structural effect of nanoparticle agglomerates on filtration. They showed that at the same mobility size, agglomerates had lower penetration due to larger interception length. Buha et al. (2013) studied agglomerate filtration and analyzed effect of the agglomerate correction on filtration efficiency. Seto et al. (2010) and Wang et al. (2011a, b) investigated filtration of carbon nanotubes (CNTs). These studies showed that CNT penetration was lower than that of spheres of the same mobility size due to the longer geometric length. Bahk et al. (2013) used the filtration method to determine the length of CNTs. Vo and Zhuang (2013) measured the CNT penetration for facepiece respirators and also reported lower penetration than spheres.

In addition to screen filters, standard fibrous filters, and respirator filters, nanoparticle penetration has been tested on other types of filters. Wang et al. (2008a, b) tested filtration efficiency of nanofiber filter media against nanoparticles and analyzed the figure of merit for different particle sizes. Cyrs et al. (2010) and Chen et al. (2013a) measured nanoparticle collection efficiency by capillary pore membrane filters. These studies demonstrated collection of nanoparticles for electron microscopic and exposure assessment. Chen et al. (2013b) extended the study to nanoparticle agglomerates. They found that the agglomerate length needs to be considered for interception and alignment of agglomerates with the flow was observed at high velocities. Liu et al. (2011) obtained filtration efficiency of membranecoated filters against nanoparticles. Brochot et al. (2011) measured nanoparticle penetration in two fibrous media.

Yang and Lee (2005) studied filtration of a fibrous filter pretreated with anionic surfactants. Huang et al. (2007) studied penetration of $4.5 \mathrm{~nm}$ to $10 \mu \mathrm{m}$ aerosol particles through fibrous filters. Both the above studies manipulated the filter charge and demonstrated importance of electrostatic effect. Steffens and Coury (2007a, b) measured filtration efficiency against particles generated by an electrospray. Otani et al. (2007) and Furuuchi et al. (2010) used fibrous filters for inertial classification and sampling of nanoparticles. They showed that at high face velocity $(\sim 50 \mathrm{~m} /$ s), the inertial effect should be considered for nanoparticles.

Table 1 provides an overview of the experimental studies for nanoparticle filtration, including brief information of the particle material and size, filter media, face velocity, and testing methods. 


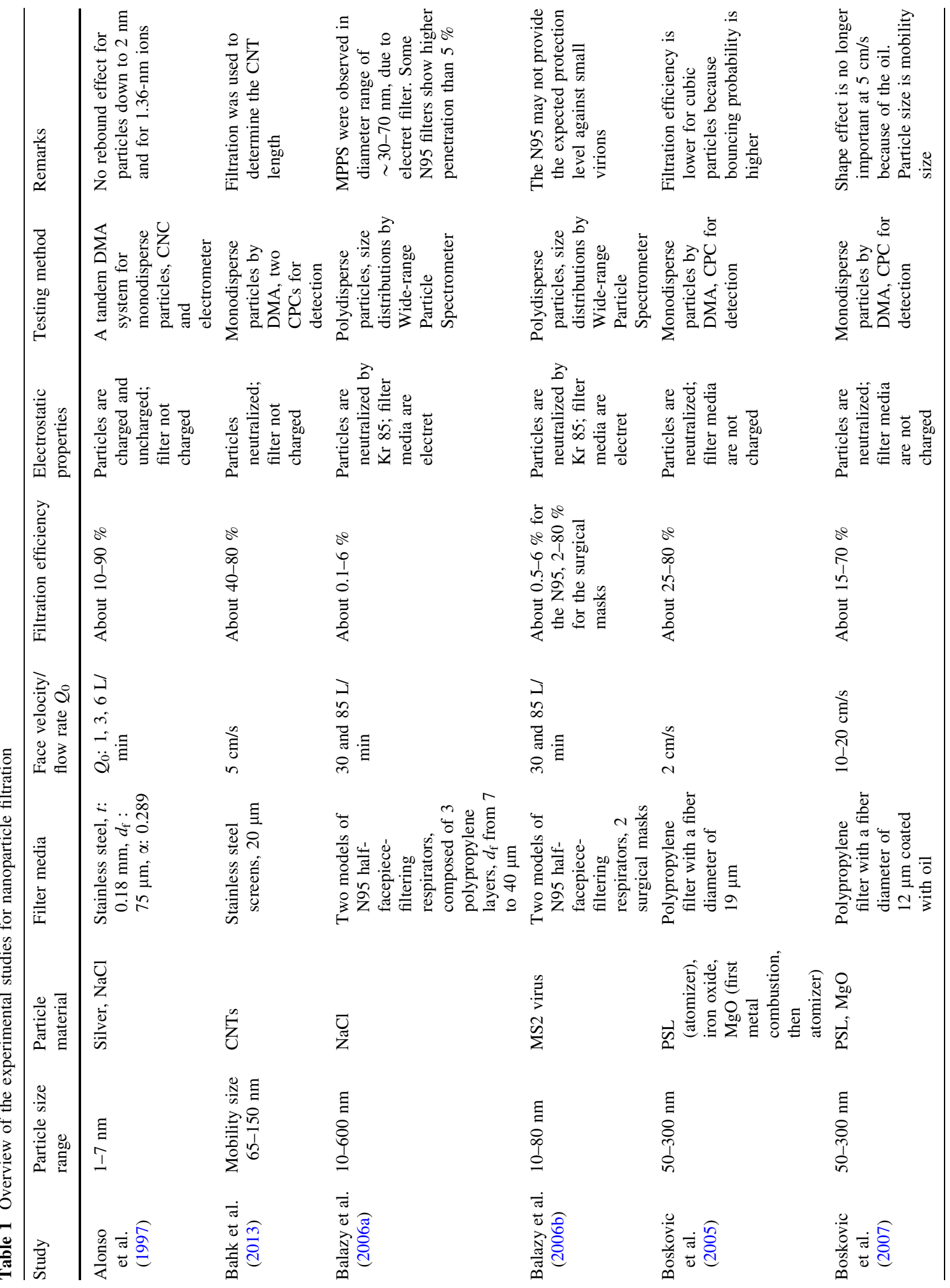




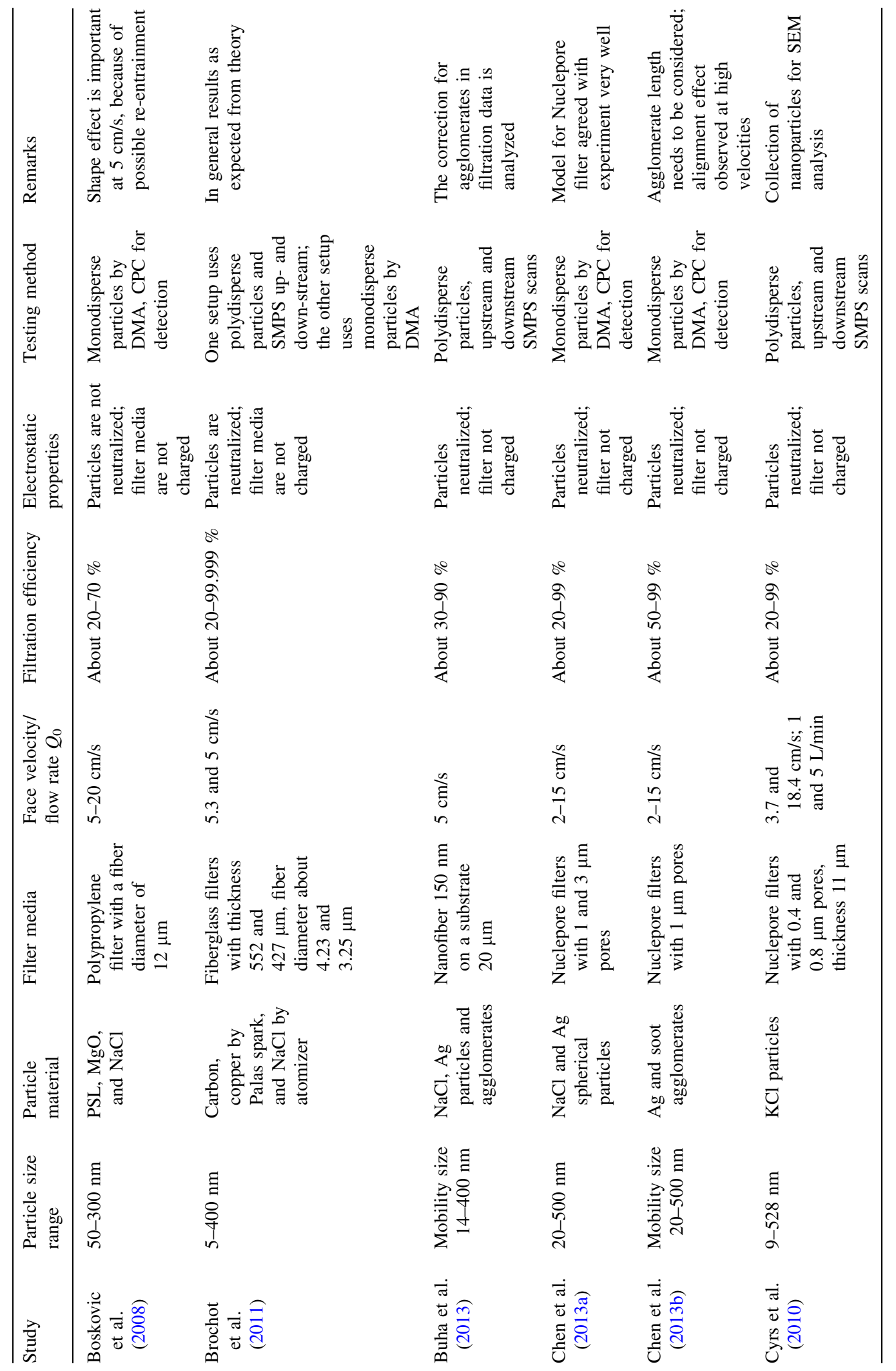




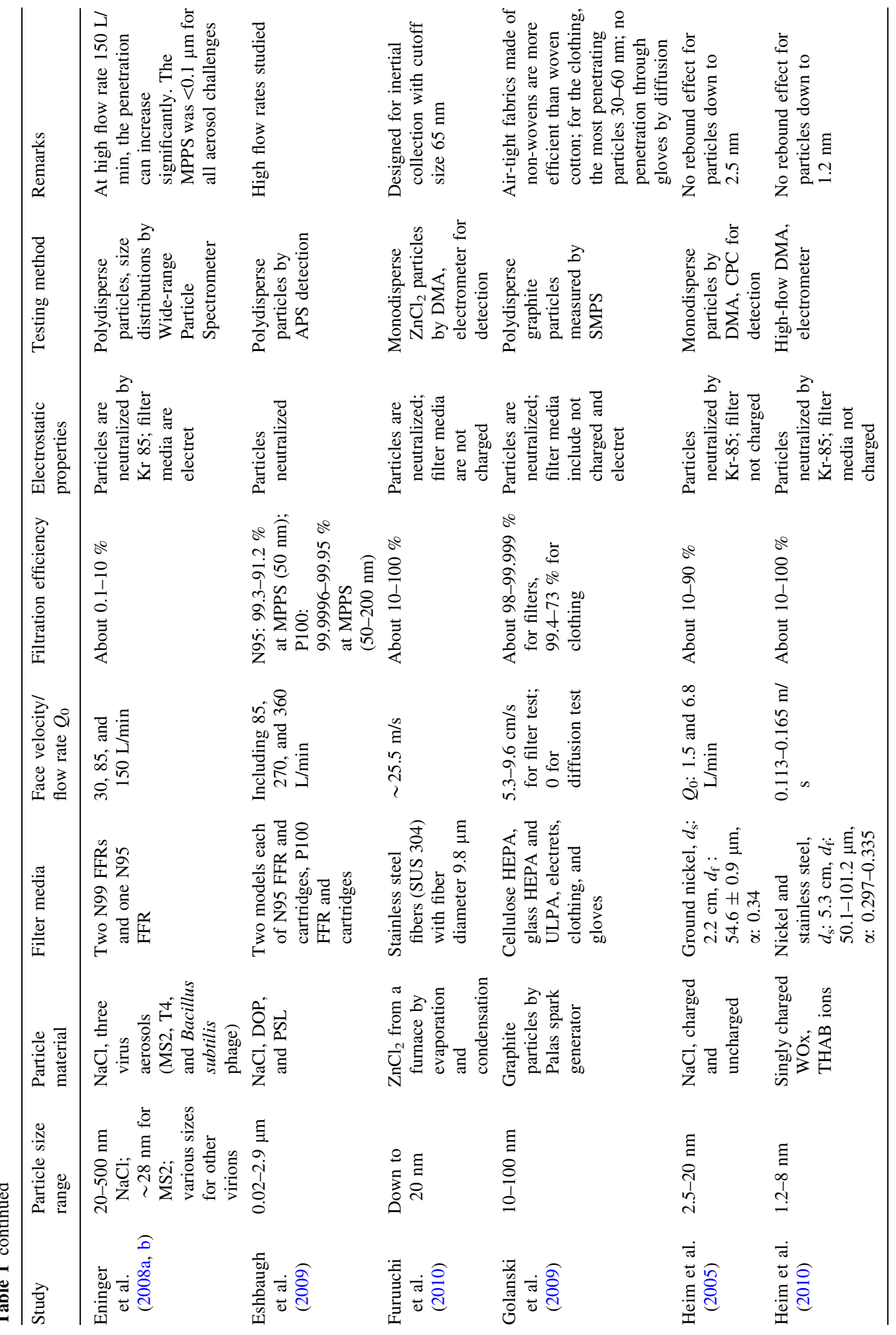




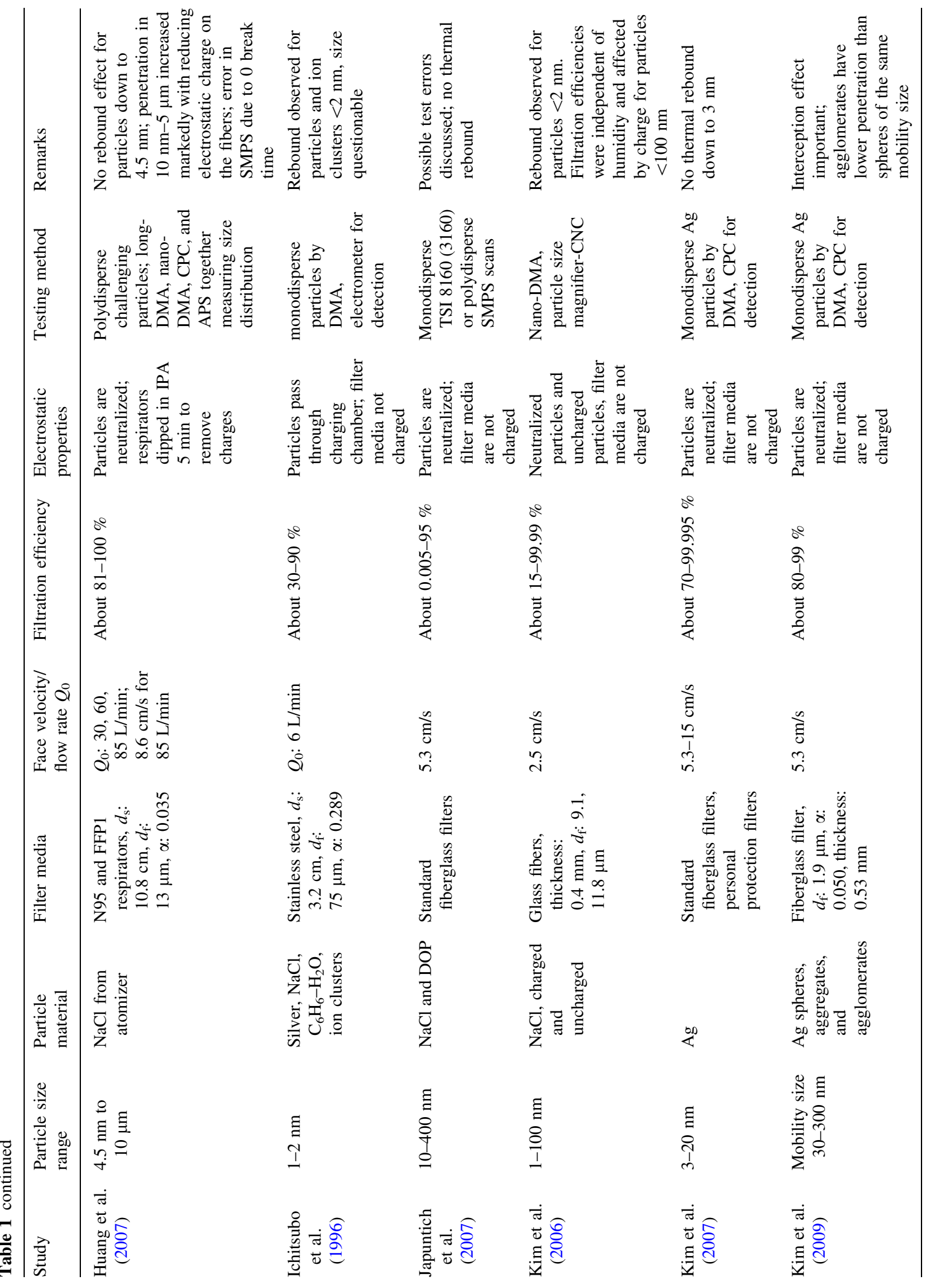




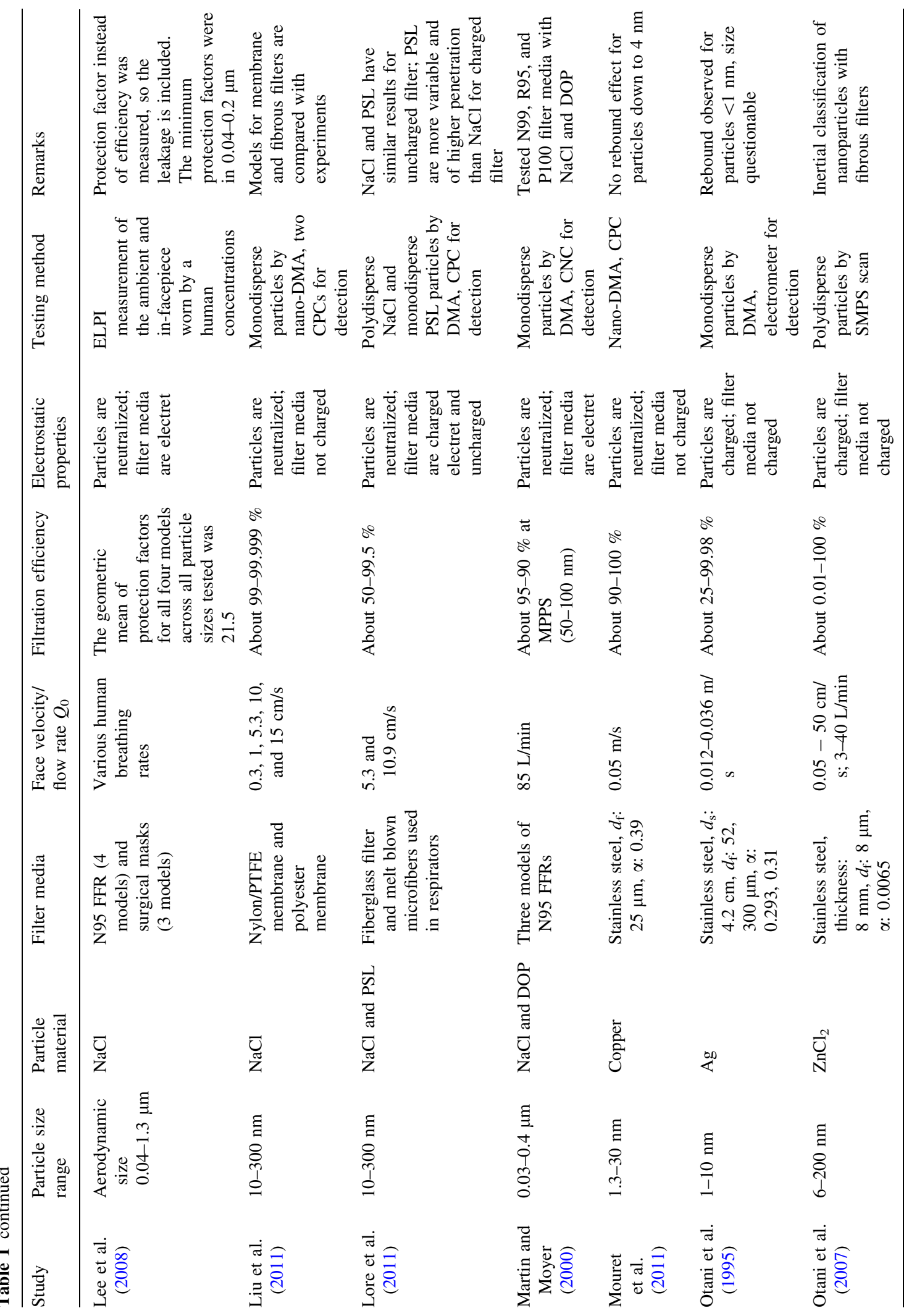




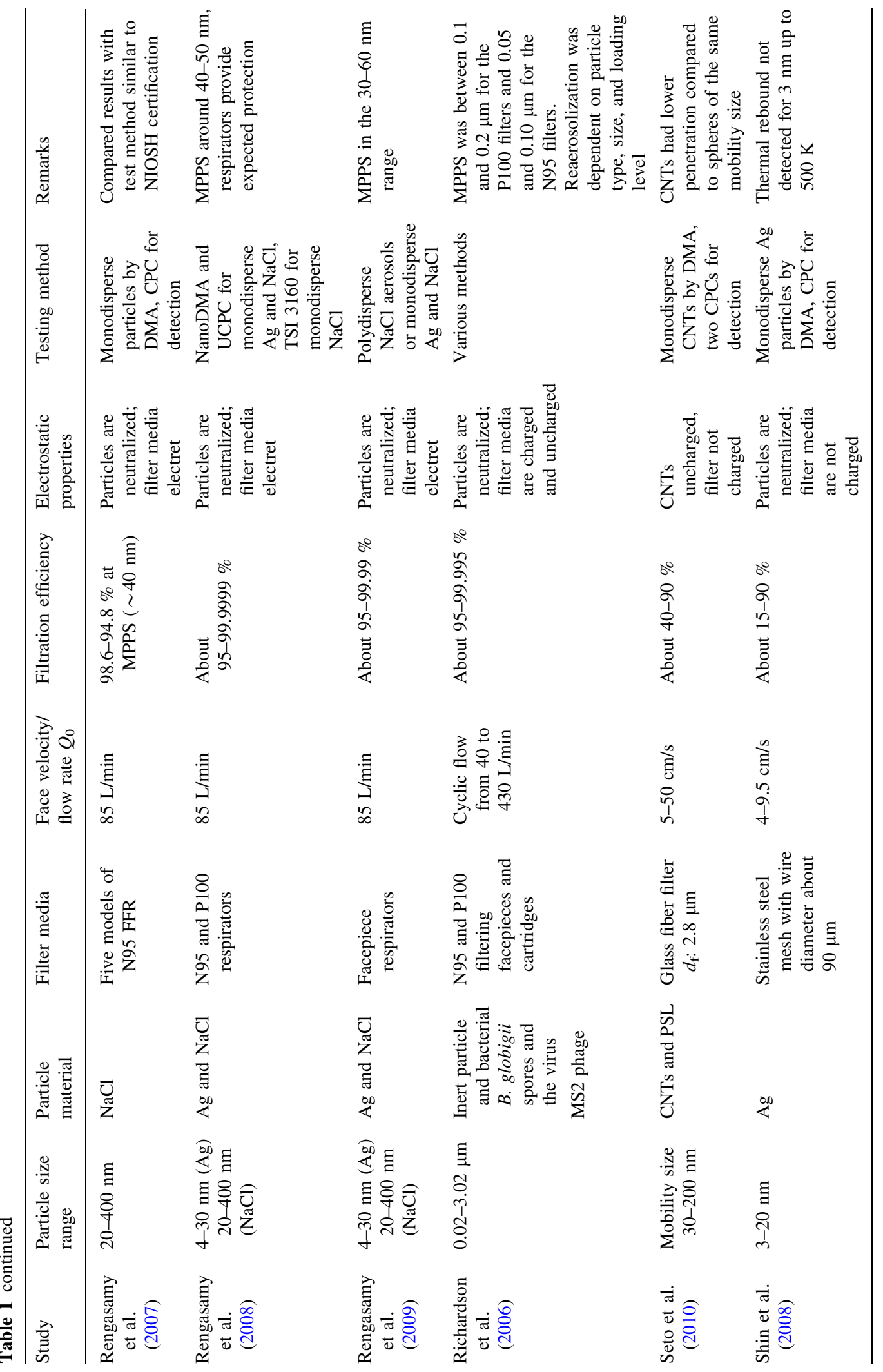




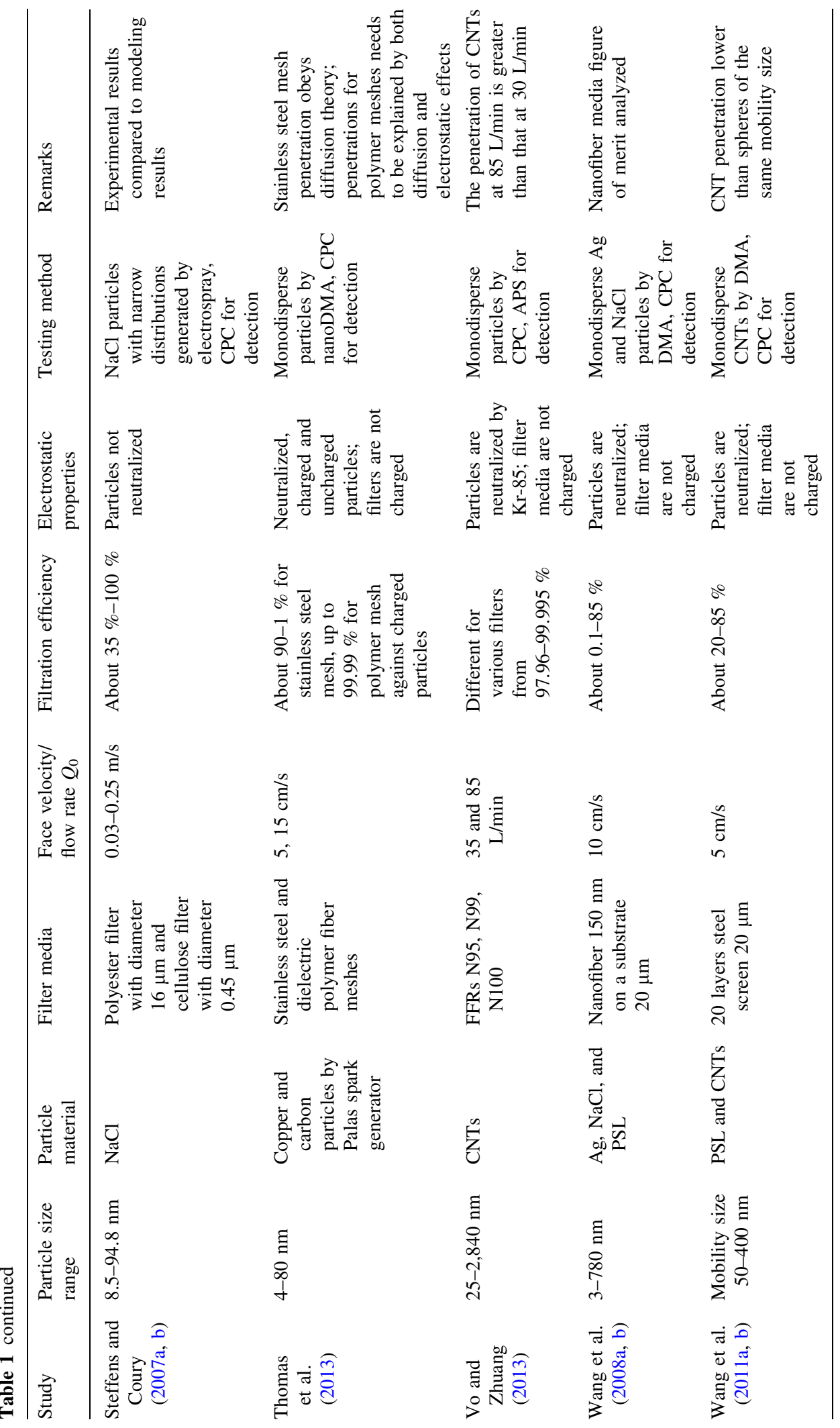




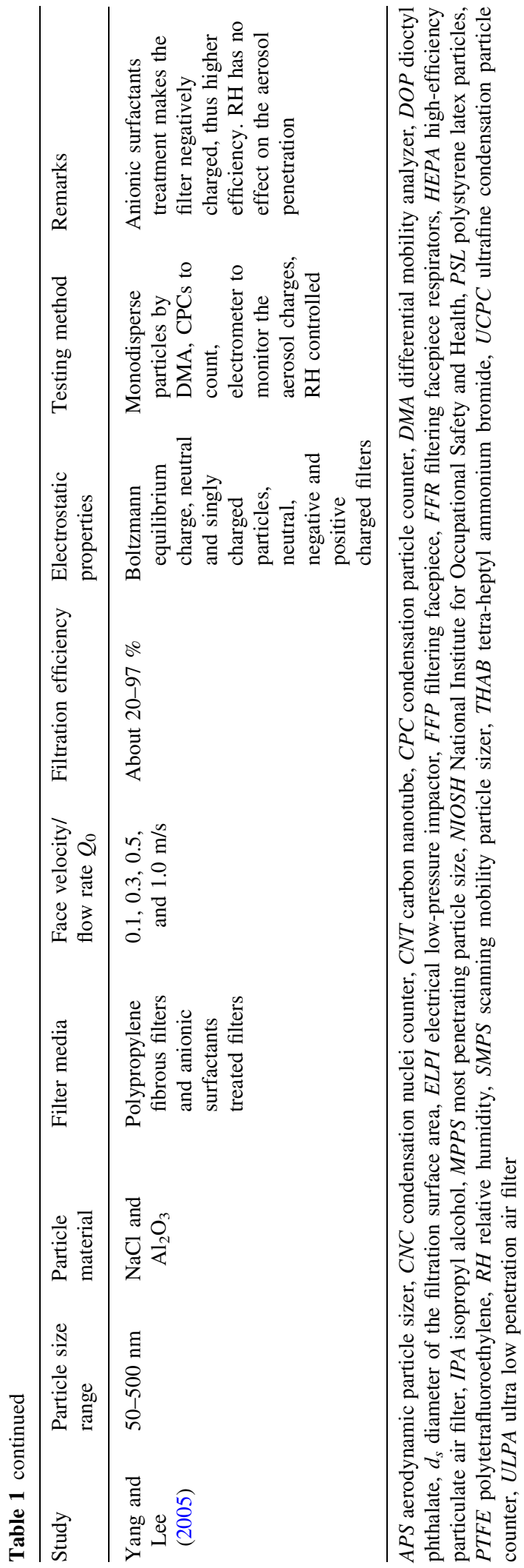

\section{Testing methods and instruments}

The basic method to test the efficiency of a filter is to challenge the filter with testing aerosol particles, quantify the particle concentrations upstream and downstream of the filter, and then calculate the efficiency using Eqs. 1 and 2. The filtration testing system usually consists of an aerosol generation part, particle measurement part, filter holder system, and other parts for pressure measurement, flow control, etc.

\section{Generators for testing aerosols}

The atomization method, evaporation/condensation method, and spark generation method have all been used for generation of nanometer aerosols in filtration tests. The atomization method produces aerosol particles from liquid solutions or suspensions by breaking the liquid into airborne droplets. The operating pressure of compressed-air type atomizers is usually in the range of 100 to several hundred $\mathrm{kPa}$. The droplet size distributions usually have the mass median diameter around several micrometers and the geometric standard deviation around 1.5-3 (see Table 2). When the atomizer is used with liquids of low volatility, such as di(2-ethylhexyl) phthalate (DOP, vapor pressure $3.5 \times 10^{-6} \mathrm{~Pa}$ at $293 \mathrm{~K}$ ), di(2-ethylhexyl) sebacate (DEHS or DOS), oleic acid (vapor pressure $0.012 \mathrm{~Pa}$ at $293 \mathrm{~K}$ ), mineral oil, and silicone oil, droplet aerosols can be produced whose size is stable for hundreds of seconds (Hinds 1999). When the atomizer is used with a volatile solvent containing dissolved solid material, e.g., salt, the solvent evaporates quickly in micron-sized droplets and solid aerosol particles are formed. Similarly, when the atomizer is used with a suspension containing solid particles, e.g., PSL, the liquid in the droplets evaporates and solid aerosol particles are produced.

Table 2 lists parameters of some commercial atomizer aerosol generators. These atomizers provide defined polydisperse aerosols under normal operation conditions. The total aerosol concentration ranges from $10^{6} \# / \mathrm{cm}^{3}$ to over $10^{8} \# / \mathrm{cm}^{3}$. The number mean or median diameter of the produced aerosol is usually in the range of $100-500 \mathrm{~nm}$ when DOP or DOS is used. There are fractions of these particle size distributions which are below $100 \mathrm{~nm}$. Japuntich et al. (2007) used atomizer-generated DOP particles 


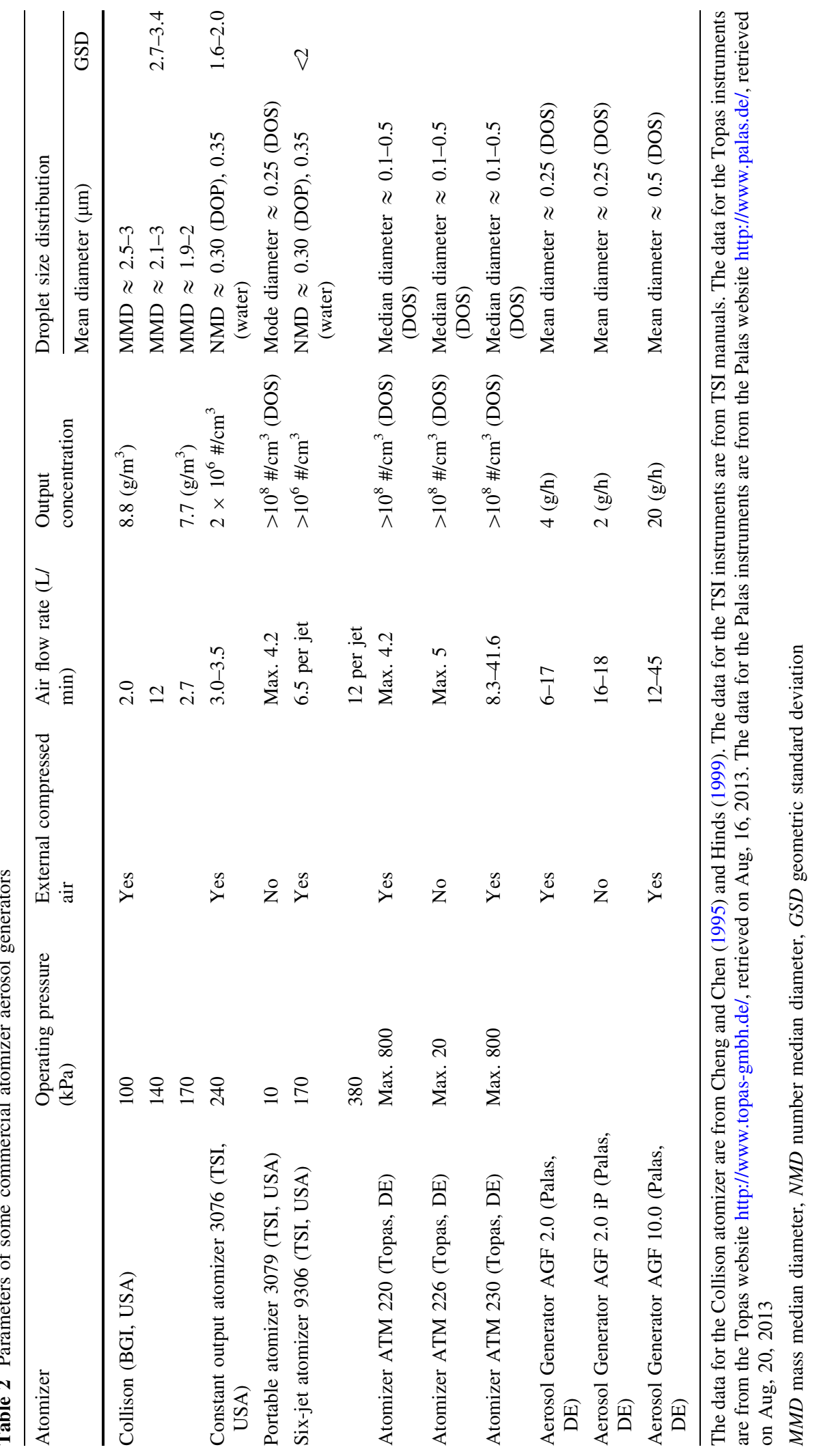


Table 3 The calculated size of solid particles based on the droplet size and solid volume fraction

\begin{tabular}{lcccc}
\hline $\begin{array}{l}\text { Solid volume } \\
\text { fraction (\%) }\end{array}$ & \multicolumn{4}{l}{ Dried solid particle size $(\mathrm{nm})$} \\
\cline { 2 - 5 } & $\begin{array}{l}\text { Droplet } \\
300 \mathrm{~nm}\end{array}$ & $\begin{array}{c}\text { Droplet } \\
500 \mathrm{~nm}\end{array}$ & $\begin{array}{l}\text { Droplet } \\
1000 \mathrm{~nm}\end{array}$ & $\begin{array}{l}\text { Droplet } \\
3000 \mathrm{~nm}\end{array}$ \\
\hline 5 & 110.5 & 184.2 & 368.4 & 1105.2 \\
1 & 64.6 & 107.7 & 215.4 & 646.3 \\
0.5 & 51.3 & 85.5 & 171.0 & 513.0 \\
0.1 & 30.0 & 50.0 & 100.0 & 300.0 \\
0.05 & 23.8 & 39.7 & 79.4 & 238.1 \\
0.01 & 13.9 & 23.2 & 46.4 & 139.2 \\
\hline
\end{tabular}

to test fiberglass filters. When solution of dissolved solid is used, the size of dried solid particles depends on both the droplet size and solid concentration. The size of the solid particle $d_{\mathrm{p}}$ can be calculated from the droplet size $d_{\mathrm{d}}$ and the volume fraction of the solid material $F_{\mathrm{v}}$ (Hinds 1999),

$d_{\mathrm{p}}=d_{\mathrm{d}}\left(F_{\mathrm{v}}\right)^{1 / 3}$.

Table 3 gives the calculated size of solid particles based on the droplet size and solid volume fraction. It is clear that the solid particle size can be adjusted by changing the solid concentration in the solution, so that the particles of desired size can be produced for filtration tests. The TSI 3160 automated filter tested uses this strategy to generate salt particles of different sizes. Many of the studies listed in Table 1 used salt particles generated from atomizers for filtration tests. The size range of these particles is usually above $15 \mathrm{~nm}$, because the particle concentration below $15 \mathrm{~nm}$ is low which causes difficulty for tests of high-efficiency filters.

The evaporation and condensation method with a furnace has been used to generate metal nanoparticles for filtration studies, especially in the range below $30 \mathrm{~nm}$ (Kim et al. 2007, Shin et al. 2008, Rengasamy et al. 2008, 2009). Silver is often used in such a method due to its stability in air and relatively low melting point. For example, silver slugs (99.99\% metal based) with suitable dimensions can be placed in a ceramic boat and positioned in the middle of an electrical tube furnace, where the silver is heated to $850-1,400{ }^{\circ} \mathrm{C}$ (dependent on the furnace). A carrier gas flow, e.g., nitrogen, can be passed through the tube furnace and carry the silver vapor out. As the temperature decreases, condensation of the silver vapor leads to

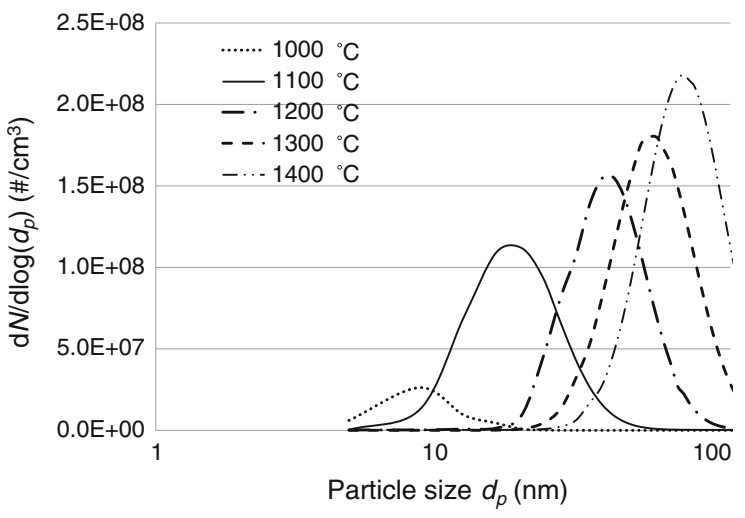

Fig. 3 Size distribution of the silver nanoparticles generated by a tube furnace at different temperatures

Table 4 Information of some commercial tube furnaces

\begin{tabular}{lll}
\hline Furnace model & $\begin{array}{l}\text { Temperature } \\
\text { range }\end{array}$ & $\begin{array}{l}\text { Power } \\
(\mathrm{kW})\end{array}$ \\
\hline $\begin{array}{l}\text { Lindberg/BlueM model: } \\
\text { STF55433C-1 }\end{array}$ & Max. $1500{ }^{\circ} \mathrm{C}$ & 6.0 \\
$\begin{array}{l}\text { Lindberg/BlueM model: } \\
\begin{array}{l}\text { CC58114A } \\
\text { Carbolite model: STF } 16 / 180\end{array}\end{array}$ & Max. $1200{ }^{\circ} \mathrm{C}$ & 3.6 \\
\hline
\end{tabular}

nanoparticles. The particle size distribution depends on the temperature and carrier flow rate. An example of the size distributions of silver particles generated by this method is shown in Fig. 3. It shows that the particle concentration and mode size increases with the furnace temperature, due to the higher evaporation rate. The total aerosol concentration ranges from $10^{6}$ $\# / \mathrm{cm}^{3}$ to over $10^{8} \# / \mathrm{cm}^{3}$. Relatively low temperatures $\left(<1,150{ }^{\circ} \mathrm{C}\right)$ may be better suited for generation of particles below $30 \mathrm{~nm}$. Buha et al. (2013) reported that the particle generation system was stable during their filtration experiments. Particle concentration at the peak and the standard deviation of the size distribution varied within $20 \%$. The peak location varied by a few nanometers. Information of some commercial tube furnaces is given in Table 4.

The mode of the particle size distribution generated by the atomization method is generally larger than that by the furnace method; both methods can generate enough particles in the range from 15 to $30 \mathrm{~nm}$ for filtration tests. The overlapping range can be used to check consistency of the two methods. Since diffusion is the dominant filtration mechanism for particles well 
Table 5 Information for two models of the Palas spark generators

\begin{tabular}{lllllll}
\hline Model & Carrier gas & $\begin{array}{l}\text { Carrier gas } \\
\text { flow rate } \\
(\mathrm{L} / \mathrm{min})\end{array}$ & $\begin{array}{l}\text { Volume } \\
\text { flow rate } \\
(\mathrm{L} / \mathrm{min})\end{array}$ & Output concentration & $\begin{array}{l}\text { Primary } \\
\text { particle } \\
\text { size }(\mathrm{nm})\end{array}$ & $\begin{array}{l}\text { Agglomerate } \\
\text { size }(\mathrm{nm})\end{array}$ \\
\hline GFG-1000 & Argon & $4-6$ & $0-40$ & $>10^{7} \# / \mathrm{cm}^{3}$ & $3-5$ & $0-150$ \\
DNP-2000 & Nitrogen & $4-6$ & $0-40$ & $>10^{7} \# / \mathrm{cm}^{3}$ & $3-5$ & $20-150$ \\
\hline
\end{tabular}

Data except GSD are from the Palas website http://www.palas.de/, retrieved on Aug, 16, 2013. The GSD is from Liu et al. (2012)

below $100 \mathrm{~nm}$, the particle material almost does not affect the efficiency. The filtration efficiencies for silver and salt particles are expected to be almost the same in the overlapping range.

Nanoparticles generated by spark discharge have been used in a number of filtration studies (Golanski et al. 2009; Brochot et al. 2011; Mouret et al. 2011; Thomas et al. 2013), including carbon and copper particles. This technique employs periodic spark discharge to vaporize electrode materials and subsequent nucleation/condensation to form nanoparticles (Schwyn et al. 1988). Liu et al. (2012) pointed out that the temperature generated at the instant of spark discharge is much higher than the typical upper limit of a tube furnace. Thus, even materials with very high melting point can be used in a spark generator if they are conductive. Liu et al. (2012) showed that the spark generator was capable of generating nanoparticles at high mass output with stable characteristics over many hours. Commercial spark generators are available in the market and information is provided in Table 5 . The primary particles from the spark generate are very small, in the 3-5 nm range for carbon, and 6-12 nm range for metals including silver, gold, and nickel (Liu et al. 2012). The larger particles from 20 to $150 \mathrm{~nm}$ are agglomerates.

\section{Aerosol detection instruments}

To quantify the particle concentrations upstream and downstream of the filter, instruments for aerosol detection are needed. The particle concentration may be based on mass, surface area, or number.

TSI 8130 Automated Filter Tester uses polydisperse $\mathrm{NaCl}$ or oil particles and two photometers to measure total mass concentrations up- and downstream of the filter. The photometers rely on light scattering from multiple particles to obtain a relative concentration measurement. The signal voltage is proportional to the mass of aerosol sampled by the photometer. The dynamic range of the TSI photometers is $1.0 \mu \mathrm{g} / \mathrm{m}^{3}$ to $>200 \mathrm{mg} / \mathrm{m}^{3}$ (TSI 2008). It should be noted that light scattering is heavily dependent on the particle size. In the Rayleigh regime (particles much smaller than the wavelength of light), the scattered intensity is proportional to the sixth power of the particle diameter. Therefore, the photometer favors detection of large particles, and is not sensitive for exceedingly small nanoparticles.

Stanley et al. (2010) used the nanoparticle surface area monitor (NSAM, TSI 3550, USA) to measure upand down-stream surface area concentrations to evaluate filters. Compared to the mass or volume, surface area is more sensitive for nanoparticles. In addition, some toxicological studies suggested the total surface area of airborne nanoparticles as a more relevant measure of health-relevant effects (Oberdörster et al. 1995; Donaldson et al. 1998). NSAM measures the nanoparticle surface area deposited in two regions, trancheobronchial and alveolar of the human lung. The applicable size range is about $20-400 \mathrm{~nm}$.

The number concentration is the most sensitive parameter for nanoparticles and is commonly used in filtration tests of nanoparticles. The condensation particle counters (CPCs), sometimes called condensation nuclei counters (CNCs), are by far the most used instruments for measurement of the number concentration of nanoparticles (see Table 1). CPCs saturate an aerosol by vapor of certain working liquids, then create supersaturation by adiabatic expansion or flow through a cold tube, and thus condense the vapor on the aerosol. Therefore, the aerosol particles grow to a size which can be readily detected by optical counters. The number concentration of the aerosol is then determined by single-particle counting or by calibrated light-scattering measurement (photometric mode). Commonly used working liquids include $n$ butyl alcohol, isopropyl alcohol, and water (see 


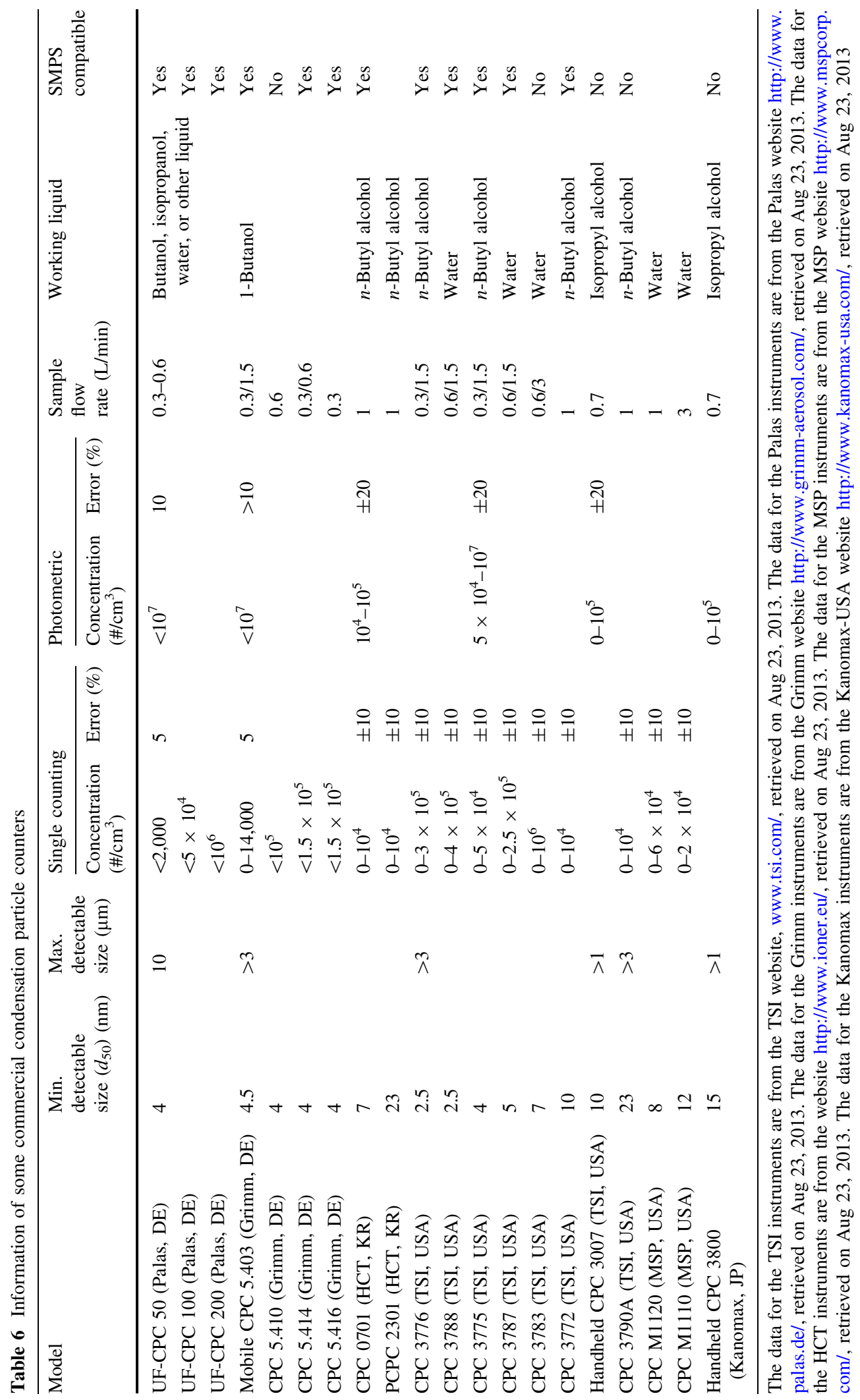


Table 6). Compared to water, alcohol working liquids provide better detection of hydrophobic particles near the detection limit, such as oily or combustiongenerated particles covered by organics. However, alcohol vapors can be emitted from the CPC, causing concerns for human exposure, or problems for nearby gas analyzers, or airborne contaminants, e.g., in semiconductor industry. Water is more environmentally friendly and easier to acquire and dispose. Highpurity water is usually required in the CPCs. A CPC can be combined with a particle size classifier, so that particles of different sizes can be counted separately, which leads to the particle size distribution. The DMA usually serves as the particle classifier, and the combination of DMA and CPC with controlling software gives rise to the scanning mobility particle sizer (SMPS). More discussion on DMA and SMPS follows in the next section. Some CPCs are equipped with built-in SMPS compatibility, which is indicated in Table 6.

The information in Table 6 shows that state-of-theart commercial CPCs can detect particles down to $2.5 \mathrm{~nm}$. Detection of particles below $2 \mathrm{~nm}$ has been achieved (Sgro and Fernandez de la Mora 2004; Iida et al. 2009; Vanhanen et al. 2011). However, the instruments and working liquids in these studies are for specific research purposes. Kim et al. (2006) used a system composed of a PSM and a condensation nuclei counter to measure the filtration efficiency of $\mathrm{NaCl}$ particles down to $1 \mathrm{~nm}$. The PSM is similar to a CPC but without the optical counter. In the PSM, particles can grow in a supersaturated atmosphere created by the mixing of a hot saturated stream with a cold aerosol flow. The particles grow to a certain size and then are sent to a regular CPC to be detected.

Some researchers used an electrometer to measure the current carried by the aerosols and obtained the number concentration indirectly (Otani et al. 1995, Ichitsubo et al. 1996, Furuuchi et al. 2010, Heim et al. 2010). The particles classified by the DMA mostly carry a single electrical charge, thus the number concentration can be computed based on the current carried by the aerosol and the flow rate. This method can be applied to very small particles below $2 \mathrm{~nm}$. Detection by the electrometer dictates that the challenging particles in the filtration experiments must be charged. Therefore, the electrostatic effect plays a role in the filtration experiments. The charging status in practical filters is usually complicated and difficult to determine accurately; therefore, modeling the data obtained by this method is challenging.

\section{Particle size measurement instruments}

The particle size plays an essential role in filtration. Therefore, accurate measurement of the particles size is critical for reliable filtration data. For airborne nanoparticles, electrical mobility measurement represents the most accurate and widely used method to determine the particle size. Other methods, such as the laser optical sizer and electrical low-pressure impactor, have also been used in filtration studies.

The electrical mobility characterizes the readiness of a particle moving in an electrical field. The electrical mobility is higher if the particle has more charges or if the particle size is smaller. When the particle charge is known, measurement of the electrical mobility gives the particle size. The DMA separates particles according to their mobility, and can be used to select monodisperse particles from a polydisperse aerosol population. Thus it can measure the particle size or provide monodisperse aerosols as the challenging particles for a filtration test. Many types of DMAs have been developed (Liu and Pui 1974; Winkelmayr et al. 1991; Pourprix and Daval 1990; Zhang et al. 1995; Chen et al. 1998; Rosser and Fernandez de la Mora 2003, among others). Information of some commercial DMAs is listed in Table 7.

The DMA resolution, or the degree of monodispersity of the exiting particles, is critical for accurate measurement. The DMA resolution depends on the DMA geometry and the flow rates. At the same time, high transmission efficiency is desired for the DMA so that excessive particle loss can be avoided. The strong diffusion of nanoparticles poses difficulties for the DMA to achieve these goals. Chen et al. (1998) pointed out that the diffusion broadening effect in the transfer function becomes very pronounced below $10 \mathrm{~nm}$, resulting in the deterioration of sizing resolution. In addition, the diffusion loss in the aerosol transport passages is significant for particle size below $10 \mathrm{~nm}$, resulting in the deterioration of detection sensitivity. To alleviate these problems, the aerosol passage is shortened to a minimum while maintaining a laminar and steady flow at the entrance slit of the TSI nano-DMA (Chen et al. 1998). It can be seen from Table 7 that the DMAs designed for the nanoparticle range have shorter height. This feature reduces the 
Table 7 Information of some commercial DMAs

\begin{tabular}{|c|c|c|c|c|c|c|}
\hline Model & $\begin{array}{l}\text { Particle size } \\
\text { range }(\mathrm{nm})\end{array}$ & $\begin{array}{l}\text { Aerosol flow rate } \\
(\mathrm{L} / \mathrm{min})\end{array}$ & $\begin{array}{l}\text { Sheath air flow rate } \\
(\mathrm{L} / \mathrm{min})\end{array}$ & $\begin{array}{l}\text { Max input } \\
\text { concentration }\end{array}$ & Voltage & $\begin{array}{l}\text { Dimension } \\
(\mathrm{mm})\end{array}$ \\
\hline $\begin{array}{l}\text { L-DMA 55-900 } \\
\text { (Grimm, DE) }\end{array}$ & $4.2-1,110$ & 0.3 & $3-20$ & $10^{8} \# / \mathrm{cm}^{3}$ & $5-10,000 \mathrm{~V}$ & $492(\mathrm{H})$ \\
\hline $\begin{array}{l}\text { M-DMA 55-340 } \\
(\text { Grimm, DE })\end{array}$ & $2.1-358$ & 0.3 & & & & $230(\mathrm{H})$ \\
\hline $\begin{array}{l}\text { S-DMA 55-100 } \\
\text { (Grimm, DE) }\end{array}$ & $0.9-112$ & $1-5$ & & & & $157(\mathrm{H})$ \\
\hline DMA-20 (HCT, KR) & $7-830$ & $0.1-1.5$ & $1-15$ & $10^{7} \# / \mathrm{cm}^{3}$ at & $10-10,000$ & $420 \times 76$ \\
\hline DMA-40 (HCT, KR) & $10-700$ & & & $10 \mathrm{~nm}$ & VDC & $650 \times 44$ \\
\hline DMA-05 (HCT, KR) & $2-160$ & & & & & $210 \times 36$ \\
\hline $\begin{array}{l}\text { DEMC } 2000 \text { (Palas, } \\
\text { DE) }\end{array}$ & $8-1,200$ & $0-4$ & $0-10$ & & & $570 \times 150$ \\
\hline $\begin{array}{l}\text { DEMC } 1000 \text { (Palas, } \\
\text { DE) }\end{array}$ & $4-600$ & $0-4$ & $0-10$ & & & \\
\hline $\begin{array}{l}\text { Long-DMA } 3081 \\
\text { (TSI USA) }\end{array}$ & $10-1,000$ & $0.2-2$ & $2-15$ & $\begin{array}{l}10^{8} \# / \mathrm{cm}^{3} \text { at } \\
10 \mathrm{~nm}\end{array}$ & $\begin{array}{l}10-10,000 \\
\text { VDC }\end{array}$ & $610 \times 76$ \\
\hline $\begin{array}{l}\text { nano-DMA } 3085 \\
\text { (TSI USA) }\end{array}$ & $2-150$ & $0.3-3$ & $3-20$ & & & $203 \times 79$ \\
\hline
\end{tabular}

The dimension represents the height $\times$ the outer diameter. The data for the TSI instruments are from the TSI website, www.tsi.com/, retrieved on Aug 23, 2013. The data for the Palas instruments are from the Palas website http://www.palas.de/, retrieved on Aug 23, 2013. The data for the Grimm instruments are from the Grimm website http://www.grimm-aerosol.com/, retrieved on Aug $23,2013$. The data for the HCT instruments are from the website http://www.ioner.eu/, retrieved on Aug 23, 2013

residence time of the particles in the DMA column, thus lowers the diffusion loss and lessens the deviation of the particles from the designed trajectory due to diffusion, improving the transfer function. Increasing both the sheath flow and aerosol flow rates can also reduce the residence time and achieve similar effects. High flow DMAs have been developed (Rosser and Fernandez de la Mora 2003; Fernandez de la Mora et al. 2004) and used in filtration test (Heim et al. 2010). The flow rates in practical filtration tests may be limited by the available air supplies and aerosol generators. The monodispersity of the particles can be improved by increasing the sheath flow to aerosol flow ratio. However, the higher this ratio, the more diluted the aerosol flow exiting the DMA, which cause problem for testing of high-efficiency filters. The sheath flow to aerosol flow ratio 10:1 leads to a good sizing resolution and is the most commonly used flow ratio operated by DMA users (Chen et al. 1998). The recommended TSI nano-DMA normal flow rates are $1.5 \mathrm{~L} / \mathrm{min}$ aerosol flow and $15 \mathrm{~L} / \mathrm{min}$ sheath flow. The resolution deteriorates when the particle size is exceedingly small. The TSI nano-DMA at its maximum recommended sheath air flow rate of $20 \mathrm{~L} / \mathrm{min}$ is affected by broadening to more than twice its ideal resolution for particles with an electrical mobility of $1 \mathrm{~cm}^{2} / \mathrm{V} \mathrm{s}$ (approx. $1.44 \mathrm{~nm}$ equivalent electrical mobility diameter). Usage of two DMAs in series, i.e., a tandem DMA system, can improve the sizing accuracy (Alonso et al. 1997; Yook et al. 2008). However, this approach aggravates the problem of low concentration of challenging aerosols.

The DMA and CPC can be combined to measure particle size distribution. Measuring the size distribution can be done by scanning through the DMA voltage in discrete steps. This method is slow. The particles can alternatively be classified in a timevarying electrical field, but for an exponential ramp in the field strength, there remains a one-to-one correspondence between the time a particle enters the DMA column and the time it leaves. Thus, a relation between the time-varying CPC counts and the changing DMA voltage can be established, and the correspondence between the CPC counts and the particle size can be established (Wang and Flagan 1990). This method is fast and is implemented in commercial SMPS. Information of some commercial SMPS systems is given in Table 8. Most of the systems are composed of DMA 
Table 8 Information of some commercial SMPS systems

\begin{tabular}{|c|c|c|c|c|}
\hline \multirow[t]{2}{*}{ Model } & \multicolumn{2}{|l|}{ Components } & \multirow[t]{2}{*}{ Possible scanning time } & \multirow[t]{2}{*}{ Aerosol pressure } \\
\hline & Classifier & Detector & & \\
\hline SMPS+C (Grimm, DE) & L-DMA/M-DMA & СPC5.414/CPC5.403 & \multirow{2}{*}{$\begin{array}{l}\text { A "fast scan" from } 5 \text { to } 350 \mathrm{~nm} \text { can be } \\
\text { made in }<110 \mathrm{~s}\end{array}$} & $1 \mathrm{~atm} \pm 50 \mathrm{mbar}$ \\
\hline SMPS+E (Grimm, DE) & $\begin{array}{l}\text { L-DMA/M- } \\
\text { DMA/S-DMA }\end{array}$ & $\begin{array}{l}\text { Faraday cup } \\
\text { electrometer }\end{array}$ & & $400-1,100$ mbar \\
\hline SNPS 05W (HCT, KR) & DMA-05 & WCPC & \multirow[t]{3}{*}{$75 \mathrm{~s}$} & \multirow[t]{5}{*}{$1 \pm 0.1 \mathrm{~atm}$} \\
\hline SNPS 20N (HCT, KR) & DMA-20 & $\mathrm{CPC}$ & & \\
\hline SMPS 40NW (HCT, KR) & DMA-40 & WCPC & & \\
\hline $\begin{array}{l}\text { U-SMPS 1050/1100/1200 } \\
\text { (Palas, DE) }\end{array}$ & DEMC 1000 & UF-CPC 50/100/200 & \multirow[t]{2}{*}{$\begin{array}{l}\text { A scan can be performed in as few as } \\
30 \mathrm{~s}\end{array}$} & \\
\hline $\begin{array}{l}\text { U-SMPS 2050/2100/2200 } \\
\text { (Palas, DE) }\end{array}$ & DEMC 2000 & UF-CPC 50/100/200 & & \\
\hline 3936L (TSI, USA) & DMA 3081 & $\begin{array}{l}\text { CPC } 3775 / 3776 / 3787 / \\
3788 / 3772\end{array}$ & \multirow[t]{2}{*}{$\begin{array}{l}\text { Fast scans can be performed in as few } \\
\text { as } 16 \mathrm{~s}\end{array}$} & \multirow[t]{2}{*}{$1 \pm 0.2 \mathrm{~atm}$} \\
\hline 3936N (TSI, USA) & DMA 3085 & $\begin{array}{l}\text { CPC } 3775 / 3776 / 3787 / \\
3788 / 3772\end{array}$ & & \\
\hline
\end{tabular}

The data for the TSI instruments are from the TSI website, www.tsi.com/, retrieved on Aug 23, 2013. The data for the Palas instruments are from the Palas website http://www.palas.de/, retrieved on Aug 23, 2013. The data for the Grimm instruments are from the Grimm website http://www.grimm-aerosol.com/, retrieved on Aug 23, 2013. The data for the HCT instruments are from the website http://www.ioner.eu/, retrieved on Aug 23, 2013

and $\mathrm{CPC}$, and the information of the individual components can be found in Tables 6 and 7. The SMPS +E system by Grimm consists of a DMA and an electrometer, thus the particle count is determined indirectly from the current instead of directly by CPC. Usage of CPC with internal pump in the SMPS limits the pressure of the measured aerosol, since the CPC pump needs to overcome the aerosol pressure to draw in the sample. Too much overpressure may damage the internal valves. The scan time plays a role in data inversion to map particle counts to a corresponding size. The detector response time poses limitation for how fast the scan can be performed, which is known as the smearing effect (Russell et al. 1995; Flagan 2008). The residence time of the particles in the plumbing between the DMA and the CPC should be much shorter than the counting time interval to avoid the smearing effect. With the development of CPC technology, the detector response time is getting shorter, which allows faster scans. The TSI 3936 SMPS systems have default scan time of 120-s up scan and 15-s down scan. However, recent update by TSI shows that fast scans by 3936 SMPS can be performed in $16 \mathrm{~s}$. A number of studies used SMPS to measure the particle number size distributions up- and downstream of the filter, and used the ratio to determine the penetration values (Japuntich et al. 2007; Otani et al. 2007; Golanski et al. 2009; Cyrs et al. 2010; Lore et al. 2011; Brochot et al. 2011; Buha et al. 2013).

In addition to SMPS, other instruments have been used by researchers to obtain particle size distributions up- and down-stream of the filter in filtration tests. Balazy et al. (2006a, b) and Eninger et al. (2008a, b) used the wide-range particle spectrometer (WPS, model M1000XP, MSP, USA). The WPS includes a scanning mobility spectrometer composed of a DMA and a CPC for particle measurement from 0.01 to $0.5 \mu \mathrm{m}$ and a laser particle spectrometer (LPS) for measurement in the $\sim 0.4$ to $10 \mu \mathrm{m}$ range (Liu et al. 2010). Huang et al. (2007) combined two TSI 3936 SMPS systems with the long-DMA and nano-DMA with a CPC detector and a TSI 3321 aerodynamic particle sizer (APS) to measure the penetration of $4.5 \mathrm{~nm}$ to $10 \mu \mathrm{m}$ aerosol particles through fibrous filters. The APS, which uses the time-of-flight particle sizing technology, can count and size particles ranging from 0.5 to $20 \mu \mathrm{m}$. It should be noted that the LPS and APS measure the optical equivalent particle size and aerodynamic particle size, respectively. They are different from the electrical mobility size measured by the SMPS, thus proper conversion is needed to piece together the size distribution from the nanometer 


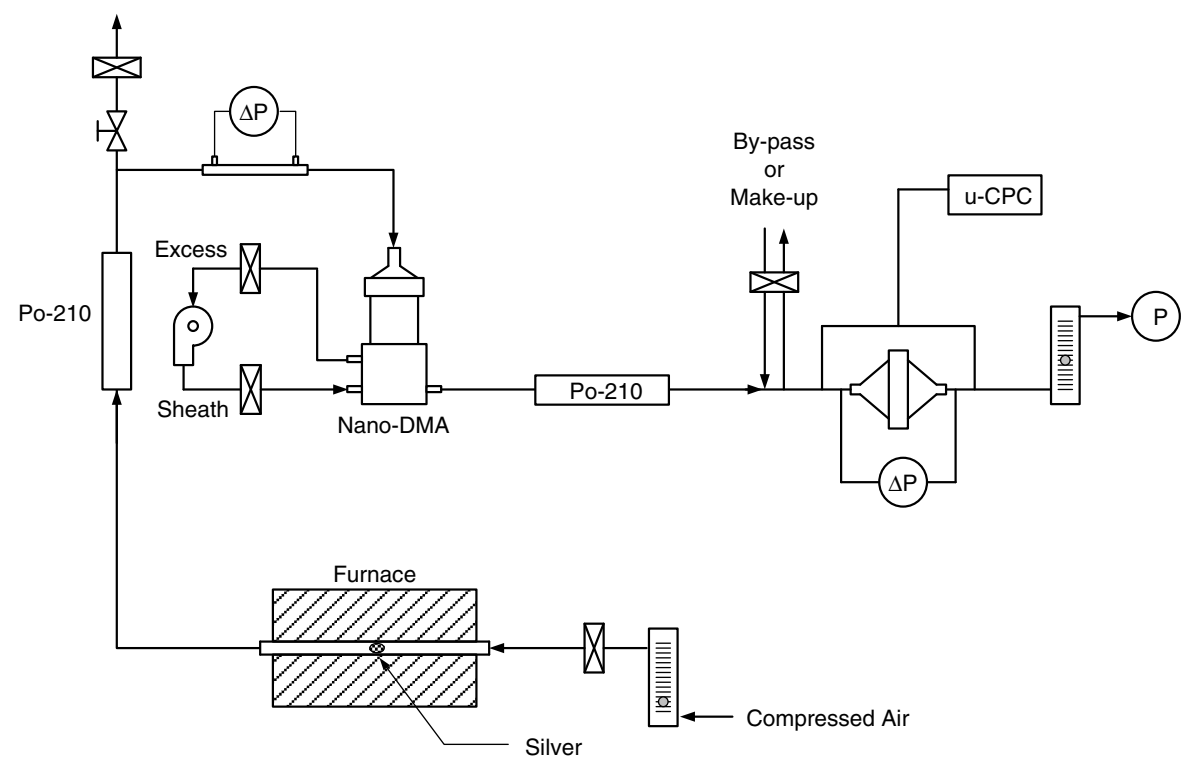

Fig. 4 Experimental setup for test using monodisperse silver nanoparticles (adapted from Kim et al. 2007)

range to the micrometer range. Lee et al. (2008) used an electrical low-pressure impactor (ELPI 3935, Dekati, Finland) to measure the particle distributions of the ambient and in-facepiece respirator worn by a human. The ELPI size selectively measures the number concentration of particles in an aerodynamic size, ranging from 0.03 to $10 \mu \mathrm{m}$, in 12 classes. The sizing resolution of ELPI is lower compared to SMPS.

Filtration experimental setup

We discuss possible filtration experimental setups. The setups in the literature can be classified in two general types: test with monodisperse aerosols and test with polydisperse aerosols.

An example of the test setup using monodisperse silver nanoparticles is shown in Fig. 4 (adapted from Kim et al. 2007). The setup consists of the particle generation part, size classification part, and filter testing part. The filtered air is used as the carrier gas, flowing through the tube furnace, and carrying the silver particles generated by the evaporation-condensation method. The test aerosol from the generator may need to be conditioned, for example by going through a diffusion dryer for evaporation of solvent when the particles are from an atomizer. The test aerosol is then neutralized in a Po-210 bi-polar charger, which gives the particles the Boltzmann equilibrium charge distribution. The bi-polar charger may be based on a radioactive source (Kr-85, Po-210 or Am-241), soft X-ray or corona discharge. A commercial DMA is usually equipped with a bi-polar charger, thus the particle charge distribution is known, and the particle size can be calculated from the electrical mobility. The flow rate of the aerosol entering the DMA can be adjusted using the valve on the excess flow route, and is measured by a laminar flow meter. The laminar flow meter measures the flow rate by the pressure drop caused by the flow through a tube with known length and diameter. The test aerosol is then classified by the DMA with a certain sheath flow rate. Knowing the aerosol flow rate into the DMA and the sheath flow rate allows monitoring of the ratio, which is indicative of the DMA sizing resolution.

The monodisperse particles exiting the DMA mostly carry one electrical charge and could be neutralized again by a Po-210 bi-polar charger. This approach reduces the electrostatic effect in filtration and the associated uncertainties. If it is desirable to completely remove charged particles, an electrical static precipitator can be added following the bi-polar charger. Before the filter, another flow path is provided for by-pass flow when the aerosol flow rate is higher than that needed through the filter holder, or for makeup air when the aerosol flow rate is lower. The flow rate through the filter holder can be calculated by 
the filtration surface area and the face velocity. In the case when makeup air is needed, good mixture should be obtained so that the particles are uniformly distributed in the air entering the filter holder. This is usually readily achieved for nanoparticles due to their low inertia and high diffusivity. Specimens of the sheet filter medium are fixed in the test filter holder and subjected to the test air flow corresponding to the prescribed filtration face velocity. The filter holder normally has a top part and a bottom part, and may be designed to hold standard $47 \mathrm{~mm}$ filter disks (Millipore Aerosol Filter Holder), filter media with a filtration surface area of $100 \mathrm{~cm}^{2}$ (TSI 8130 default holder), or filters of other sizes. The filter holder could be closed by pneumatic chucks or by screws through the top and bottom parts. Partial flows of the test aerosol are sampled up- and down-stream of the filter into a CPC, and the fractional penetration is determined from the up- and down-stream number concentrations. Furthermore the measurement of the pressure drop across the filter medium is made at the prescribed face velocity. Additional equipment is required to measure and control the test volume flow rate. Finally, the air stream goes through a final filter and into the vacuum pump.

The particle concentrations can be measured by one CPC, which takes the samples up- and down-stream of the filter sequentially. However, the line losses for the up- and down-stream sampling may be different. The difference can be significant when the particle size is very small and diffusion loss is important. In addition, some particles may be deposited at the inlet, outlet, or walls of the filter holder. Therefore, it is important to establish correction factors by performing the measurement without any filter medium in the filter holder. In this configuration, the penetration $P_{\mathrm{c}}$ is obtained. If the measured penetration when a filter is tested is $P_{\mathrm{m}}$, the corrected penetration $P$ takes the following form:

$P=P_{\mathrm{m}} / P_{\mathrm{c}}$.

The correction factor is dependent on the particle size, and should be obtained at the same particle sizes as those in the measurement for the test filter. The aerosol sample needs some time to travel through the tubing and reach the CPC. When the CPC sampling is switched from upstream to downstream, enough time intervals should be allowed to ensure that the CPC is counting the intended sample. Usually the CPC reading changes dramatically when the sampling position is changed, and stabilization of the CPC reading at a new value is an indication that the $\mathrm{CPC}$ is ready to record the new concentration.

It is also possible to utilize a dummy filter holder, which holds no filter and is placed in parallel as the filter holder with the test filter. The penetration is then obtained as ratio between the concentration downstream of the real filter holder and the concentration downstream of the dummy filter holder. The configuration requires that the two filter holders and connection lines are identical. In addition, the testing aerosol needs to be split into two streams, which may cause problem in tests of high-efficiency filters because large numbers of challenging particles are needed.

Two CPCs can be used to measure the up- and down-stream concentrations simultaneously. This method avoids switching the sampling location and the associated disturbance of the flow. The measurement time can be significantly reduced when many particle sizes are to be tested. However, different CPC units usually give somewhat different readings when sampling the same aerosol. Therefore, correction factors similar to that in Eq. 41 between the two CPCs should be obtained and used to correct the results.

A number of the CPC models listed in Table 6 have both single-particle counting mode and photometric mode. The single-particle counting mode features lower concentration range and smaller counting error compared to the photometric model. Therefore, to obtain the most accurate results, it is advisable to keep the particle concentrations both upstream and downstream of the filter in the range of the single-particle counting mode. This may be difficult to achieve when high-efficiency filters are tested. The up- and downstream concentrations may be different by more than five or six decades. A possible solution is to dilute the upstream sample which is taken into the CPC. In the TSI filter tester 3160 , the upstream sample is diluted by a factor of 100 for measurement.

The CPC reading for particle concentration is based on the total particle counts over regular preset time intervals and the flow rate. When the particle concentration is low, the CPC reading oscillates with time due to its statistical nature even with a stable aerosol sample. Using a long sampling time and taking the average value improve the accuracy of the measurement. For testing of high-efficiency filters, the 
Fig. 5 Experimental setup for test using polydisperse silver nanoparticles

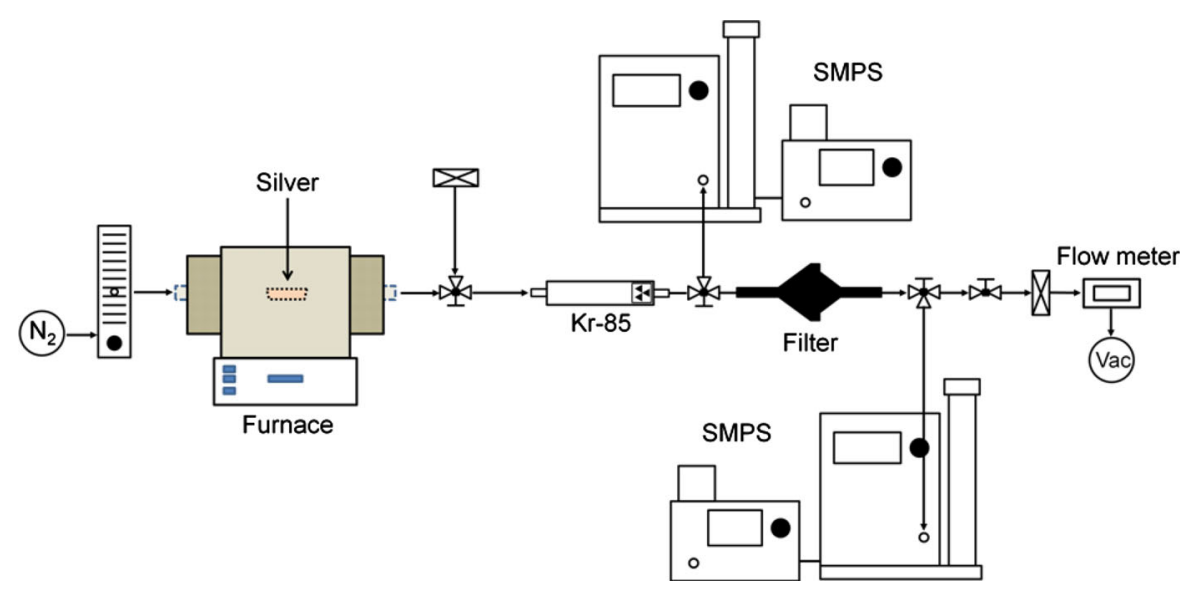

polar charger, the DMA, and finally through the CPC. For consecutive samplings of aerosol, if there is no "purge-time" pause or time interval between samples, the large classified particles left over in the system from the last sample may be erroneously counted as the smallest particles in the next sample. This error is especially serious for filter penetration if a downstream sample is taken quickly after an upstream sample. In that case, the large particles from the upstream sample are counted as small particles which may not exist at all in the penetrating downstream sample distribution, giving penetration results as much as two decades greater than reality. To avoid this error, Japuntich et al. (2007) developed a purging procedure using $16 \mathrm{~L} / \mathrm{min}$ clean air to purge the SMPS between consecutive samplings, which can be performed in less than $90 \mathrm{~s}$.

The accuracy of commercial SMPS systems, especially when the scan time is short, may be questionable (Flagan 2008). Buha et al. (2013) used 300-s scans to improve the SMPS accuracy. Japuntich et al. (2007) developed correction factor similar to those in the monodisperse test (Eq. 41) for each particle diameter channel or bin to compensate for sampling line loss and for possible SMPS software particle distribution calculation variability due to factors such as a loss in resolution at the upper and lower limits of the measured particle size ranges or low raw score counts at the upper or lower limits of the challenge particle size distribution. The variability of the correction factor increased greatly as the lower or higher range of the SMPS system was reached.

Both the monodisperse and polydisperse test particle methods can be used for nanoparticle filtration tests. With adequate calibration, the two testing 
Table 9 Information of some commercial filter test systems

\begin{tabular}{|c|c|c|c|c|c|c|}
\hline $\begin{array}{l}\text { Manufacturer } \\
\text { and model }\end{array}$ & $\begin{array}{l}\text { Particle } \\
\text { material }\end{array}$ & Particle size & Particle generation & $\begin{array}{l}\text { Flow } \\
\text { rate }\left(\mathrm{m}^{3} /\right. \\
\text { h) }\end{array}$ & $\begin{array}{l}\text { Filtration } \\
\text { efficiency } \\
(\%)\end{array}$ & Particle detector \\
\hline $\begin{array}{l}\text { Grimm } \\
7.1000\end{array}$ & $\mathrm{NaCl}$ & & $\begin{array}{l}\text { Particles from } 1 \% \mathrm{NaCl} \\
\text { solution }\end{array}$ & & $\begin{array}{l}\text { Up to } \\
99.9995\end{array}$ & $\begin{array}{l}\text { One or two } \\
\text { photometers }\end{array}$ \\
\hline $\begin{array}{l}\text { Palas MFP } \\
1000 \text { HEPA }\end{array}$ & $\begin{array}{l}\mathrm{NaCl}, \mathrm{KCl} \text {, and } \\
\text { DEHS }\end{array}$ & $\begin{array}{l}\text { Detector size range } \\
\text { down to } 60 \mathrm{~nm}\end{array}$ & Particles from atomizers & $0.54-16$ & & $\begin{array}{l}\text { Light-scattering } \\
\text { spectrometers }\end{array}$ \\
\hline $\begin{array}{l}\text { Palas MFP } \\
\text { Nano plus }\end{array}$ & $\begin{array}{l}\mathrm{NaCl}, \mathrm{KCl} \text {, and } \\
\text { DEHS }\end{array}$ & $\begin{array}{l}\text { Efficiency size range } \\
20-1000 \mathrm{~nm}\end{array}$ & & & & U-SMPS \\
\hline $\begin{array}{l}\text { TSI } 3160 \\
(8160)\end{array}$ & $\mathrm{NaCl}$ and $\mathrm{DOP}$ & $\begin{array}{l}\text { Single sizes in } \\
15-800 \mathrm{~nm} \\
\text { GSD }<1.3\end{array}$ & $\begin{array}{l}\text { Particles from atomizers } \\
\text { and classified by DMA }\end{array}$ & $0.3-6$ & $\begin{array}{l}\text { Up to } \\
99.999999\end{array}$ & Two CPCs \\
\hline $\begin{array}{l}\text { TSI } 8127 \text { and } \\
8130\end{array}$ & $\begin{array}{l}\text { DOP, DEHS, } \\
\text { and other oils } \\
\mathrm{NaCl}\end{array}$ & $\begin{array}{l}\text { CMD: } 0.2 \mu \mathrm{m}, \\
\text { GSD }<1.6^{\mathrm{a}} \\
\text { CMD: } 0.075 \mu \mathrm{m}, \\
\text { GSD }<1.86^{\mathrm{a}}\end{array}$ & Particles from atomizer & $0.9-6$ & Up to 99.999 & $\begin{array}{l}\text { Two } \\
\text { photometers }\end{array}$ \\
\hline
\end{tabular}

The data for the TSI instruments are from the TSI website, www.tsi.com/, retrieved on Aug 29, 2013. The data for the Palas instruments are from the Palas website http://www.palas.de/, retrieved on Aug 29, 2013. The data for the Grimm instruments are from the Grimm website http://www.grimm-aerosol.com/, retrieved on Aug 29, 2013. CMD: count mean diameter; GSD: geometric standard deviation

a The European version has different CMD and GSD

methods gave almost identical filtration efficiencies in the range of 20-200 $\mathrm{nm}$ for several commercial filter media (Japuntich et al. 2007). The two methods have different features. The advantages of the monodisperse test particle method include better accuracy and the ability to test high-efficiency filters using long sampling time. In contrast, the polydisperse test particle method is limited by the SMPS scan accuracy, especially at the upper or lower limits of the challenge particle size distribution. When the downstream concentration is too low, SMPS scan may not give any meaningful size distribution, thus the capability to test high-efficiency filter is limited. The disadvantages of the monodisperse test particle method include more complex flow control and longer measurement time when many particle sizes are tested. In contrast, the polydisperse test particle method has less complex setup and can deliver the filtration efficiencies for many particle sizes in shorter time.

\section{Commercial filter testing systems}

Self-contained commercial filter testing systems which could measure nanoparticles are available in the market. An overview of the systems is shown in Table 9. Grimm 7.100 Respirator Filter Testing
System is a full-fledged mass testing installation for the testing of respirator filters in accordance with European Standard EN 143. The internal generator creates aerosols from a $1 \% \mathrm{NaCl}$ solution. One or two flame photometers are used to measure the aerosol mass concentrations upstream and downstream from a filter. The connectors for filter tester and/or mask holder are standardized. The detection sensitivity is better than $10 \mathrm{ng} / \mathrm{m}^{3}$. The system measures efficiencies up to $99.9995 \%$ (penetration as low as $0.0005 \%$ ) with a test aerosol of $13 \mathrm{mg} / \mathrm{m}^{3}$.

The Palas MFP test rig is a modularly built filter test system for flat filter media and small filter elements. It can measure the fractional filtration efficiency for testing aerosols including $\mathrm{NaCl}, \mathrm{KCl}$, DEHS, etc. The filter test surface area is $100 \mathrm{~cm}^{2}$. In the model MFP 1000 HEPA, the particle measurement instrument is a light-scattering spectrometer, which can be Welas 1000 (Palas, DE) with the size range 120-2,000 nm, or model 3340 (TSI, USA) with the size range 90-7,500 nm, or HSLAS II (PMS, USA) with the size range $60-1,000 \mathrm{~nm}$. In the model MFP Nano plus, the particle measurement instrument is U-SMPS 2050 (Table 8) with the size range 5-1,000 $\mathrm{nm}$. However, determination of the fractional filtration efficiency for filter media is in the range of approximately 
Table 10 Summary of selected air filtration standards

\begin{tabular}{|c|c|c|c|}
\hline Designation & Title & Test particle & Remark \\
\hline $\begin{array}{l}\text { ANSI/ASHRAE } \\
\text { Standard } 52.2 \\
(2012)\end{array}$ & $\begin{array}{l}\text { Method of testing general ventilation air- } \\
\text { cleaning devices for removal efficiency by } \\
\text { particle size }\end{array}$ & $\begin{array}{l}\mathrm{KCl} \text { particles in the range of } \\
0.3-10 \mu \mathrm{m}\end{array}$ & $\begin{array}{l}\text { Wind tunnel test using } \\
\text { optical or aerodynamic } \\
\text { particle sizers }\end{array}$ \\
\hline EN 779 (2012) & $\begin{array}{l}\text { Particulate air filters for general } \\
\text { ventilation-determination of the } \\
\text { filtration performance }\end{array}$ & $\begin{array}{l}\text { DEHS particles in the range of } \\
0.2-3.0 \mu \mathrm{m}\end{array}$ & $\begin{array}{l}\text { Wind tunnel test using } \\
\text { optical particle sizers }\end{array}$ \\
\hline $\begin{array}{l}\text { ISO } 29463 \text { series } \\
\text { ( } 2011 \mathrm{a}, \mathrm{b}, \mathrm{c}, \mathrm{d} \text {, } \\
\text { e) }\end{array}$ & $\begin{array}{l}\text { High-efficiency filter and filter media for } \\
\text { removing particles in air }\end{array}$ & $\begin{array}{l}\text { DEHS, PAO, and Paraffin Oil in the } \\
\text { range } 0.04 \mu \mathrm{m} \text { to } 1.0 \mu \mathrm{m} \\
(0.1-2.0 \mu \mathrm{m} \text { with OPS })\end{array}$ & $\begin{array}{l}\text { Focus on the minimum } \\
\text { efficiency at the MPPS } \\
\text { and local efficiencies }\end{array}$ \\
\hline $\begin{array}{l}\text { NIOSH } 42 \text { CFR } \\
84.181(1995)\end{array}$ & $\begin{array}{l}\text { Non-powered air-purifying particulate filter } \\
\text { efficiency level determination }\end{array}$ & $\begin{array}{l}\text { A mass median aerodynamic } \\
\text { diameter of } \sim 0.3 \mu \mathrm{m}, \mathrm{NaCl} \text { or } \\
\text { DOP polydisperse particles }\end{array}$ & For respirator certification \\
\hline $\begin{array}{l}\text { EN } 1822 \text { series } \\
\text { (2009a, b, c, d, } \\
\text { e) }\end{array}$ & $\begin{array}{l}\text { High-efficiency air filters (EPA, HEPA and } \\
\text { ULPA) }\end{array}$ & $\begin{array}{l}\text { DEHS, PAO, and Paraffin Oil in the } \\
\text { range } 0.05 \mu \mathrm{m} \text { to } 0.8 \mu \mathrm{m}(0.1-2.0 \\
\text { with OPS })\end{array}$ & $\begin{array}{l}\text { Focus on the minimum } \\
\text { efficiency at the MPPS } \\
\text { and local efficiencies }\end{array}$ \\
\hline EN 143:2000 & $\begin{array}{l}\text { Respiratory protective devices-Particle } \\
\text { filters-requirements, testing, marking }\end{array}$ & $\begin{array}{l}\text { Various aerosol allowed including } \\
\text { sodium chloride and paraffin oil }\end{array}$ & $\begin{array}{l}\text { For respirator air filter } \\
\text { certification }\end{array}$ \\
\hline $\begin{array}{l}\text { ISO } \\
29461-1: 2013\end{array}$ & $\begin{array}{l}\text { Air intake filter systems for rotary } \\
\text { machinery-test methods-part 1: static } \\
\text { filter elements }\end{array}$ & $\begin{array}{l}\text { DEHS particles in the range of } \\
0.3-3.0 \mu \mathrm{m}\end{array}$ & $\begin{array}{l}\text { Wind tunnel test using } \\
\text { optical particle sizers }\end{array}$ \\
\hline
\end{tabular}

$E P A$ efficient particulate air filters, $H E P A$ high-efficiency particulate air filter, $O P S$ optical particle sizer, $U L P A$ ultra low penetration air filter, $P A O$ polyalphaolefin oil

$20-1,000 \mathrm{~nm}$. The instrument measures the particle concentration range $0-2,000 \# / \mathrm{cm}^{3}$ in the singleparticle mode, and the concentration range $2,000-10^{5}$ $\# / \mathrm{cm}^{3}$ in the photometric model. The dilution cascades enable dilution of the test aerosols by the factors 10 , $100,1,000$, and 10,000.

The filter tester models 8127 and 8130 by TSI offer testing capability for facepiece respirators and other types of filters. They are compliant with USA commercial respirator regulation 42 CFR part 84 (NIOSH 1995), European EN 143 and related respirator standards, and Japanese respirator standard. TSI 8130 uses polydisperse $\mathrm{NaCl}$ or oil particles and two photometers to measure total mass concentrations upand down-stream of the filter. The Model 8130 measures efficiencies up to $99.999 \%$ (penetrations as low as $0.001 \%$ ). The efficiency is based on total mass concentration and is heavily affected by the large ones in the challenge particle distribution.

The TSI 3160 Automated Filter Tester is a fully self-contained testing apparatus for conducting initial filter penetration tests with up to 20 different monodisperse particle sizes within a range between 15 and $800 \mathrm{~nm}$ diameter. It can be used to test both low- and high-efficiency filters and filter media, with efficiencies up to $99.999999 \%$, or penetrations down to $0.000001 \%$. The 3160 uses a bank of atomizers with solutions of different concentrations and a DMA to generate challenge DOP and $\mathrm{NaCl}$ aerosols with known sizes. Two CPCs simultaneously count the upstream and downstream particles, and computer software calculates the penetration value. The output is a curve of penetration versus particle size and produces a summary of test results, including the MPPS. TSI 3160 complies with EN 1822 parts 3 and 5. Japuntich et al. (2007) evaluated the TSI 8160 (an earlier version of the 3160 model) and noted that the manufacturer dictated a 2:1 ratio of the DMA sheath air flow rate to the aerosol flow rate, in order to give greater DMA output concentrations for the testing of very high-efficiency filters. As a result the DMA resolution is not high. The specification of the TSI 3160 states that challenge aerosols have GSD values less than 1.3. As discussed in the DMA section, higher sizing resolution is advisable for testing with particles below $10 \mathrm{~nm}$.

The commercial filter test systems provide the possibility of measurement for particles down to $15 \mathrm{~nm}$ range using polydisperse or monodisperse test particles. At the lower limit of size range, there is room 
for improvement of the techniques and development for particles below $10 \mathrm{~nm}$ is needed.

\section{Existing standardized test methods of interest to nanoparticle filtration}

A large number of standards for testing air filters exist (Table 10), covering applications in the fields of building ventilation (Tronville and Rivers 2006), gas turbine air intake, automotive cabin air, automotive engine intake, vacuum cleaner, HEPA-ULPA filter testing, respirators, etc. ISO 29463:2011 series deals with high-efficiency filters and filter media for removing particles from air. The test particle range in ISO 29463 is between 0.04 and $1.0 \mu \mathrm{m}$, and the focus is on measurement of the minimum efficiency at the MPPS. The standard focusing on filtration efficiency of airborne nanoparticles, especially for particle size down to single-digit nanometers, is still not available.

\section{Conclusion}

The applications of nanoparticle filtration increase with the development of nanotechnology and growing concerns of the environmental and health impact of nanoparticles. A review of the literature shows that significant progress has been made in nanoparticle filtration in the academic field in the recent years. Commercial instruments are already available for generation of a large amount of nanoparticles, and accurate sizing and quantification of such particles. The commercial self-contained filter test systems provide the possibility of measurement for particles down to $15 \mathrm{~nm}$ range. If state-of-the-art instruments are used as components in a filtration system, the technique can be improved at the lower limit of the size range, and filtration efficiency for particles of single-digit nanometers can be reliably tested. Current international standards dealing with efficiency test for filters and filter media focus on measurement of the minimum efficiency at the most penetrating particle size. The available knowledge and instruments provide a solid base for development of standardized test methods to determine effectiveness of filtration media against airborne nanoparticles down to single-digit nanometer range.
Acknowledgments The study is supported by the European Commission in the frame of mandate M/461 "Standardization activities regarding nanotechnologies and nanomaterials."

\section{References}

Adzumi H (1937) Studies on the flow of gaseous mixtures through capillaries. III. The flow of gaseous mixtures at medium pressures. Bull Chem Soc Jpn 12:292-303

Alonso M, Kousaka Y, Hashimoto T, Hashimoto N (1997) Penetration of nanometer-sized aerosol particles through wire screen and laminar flow tube. Aerosol Sci Technol 27:471

American Society of Heating, Refrigerating and Air-Conditioning Engineers (2012) ANSI/ASHRAE Standard 52.22012 "Method of testing general ventilation air-cleaning devices for removal efficiency by particle size". ASHRAE, Atlanta

Bahk YK, Buha J, Wang J (2013) Determination of geometrical length of airborne carbon nanotubes by electron microscopy, model calculation and filtration method. Aerosol Sci Technol 47:776-784. doi:10.1080/02786826.2013.791745

Balazy A, Toivola M, Adhikari A, Sivasubramani SK, Reponen T, Grinshpun SA (2006a) Do N95 respirators provide 95\% protection level against airborne viruses, and how adequate are surgical masks? Am J Infect Control 34:51-57

Balazy A, Toivola M, Reponen T, Podgorski A, Zimmer A, Grinshpun SA (2006b) Manikin-based performance evaluation of N95 filtering-facepiece respirators challenged with nanoparticles. Ann Occup Hyg 50:259-269

Boskovic L, Altman IS, Agranovski IE, Braddock RD, Myojo T, Choi M (2005) Influence of particle shape on filtration processes. Aerosol Sci Technol 39:1184-1190

Boskovic L, Agranovski IE, Braddock RD (2007) Filtration of nanosized particles with different shape on oil coated fibres. J Aerosol Sci 38:1220-1229

Boskovic L, Agranovski IE, Altmana IS, Braddock RD (2008) Filter efficiency as a function of nanoparticle velocity and shape. J Aerosol Sci 39:635-644

Brochot C, Mouret G, Michielsen N, Chazelet S, Thomas D (2011) Penetration of nanoparticles in $5 \mathrm{~nm}$ to $400 \mathrm{~nm}$ size range through two selected fibrous media. J Phys Conf Ser 304:012068. doi:10.1088/1742-6596/304/1/012068

Brown RC (1981) The capture of dust particles in filters by linedipole charged fibres. J Aerosol Sci 12(4):349-356

Brown RC (1993) Air filtration. Pergamon Press, London

Buha J, Fissan H, Wang J (2013) Filtration behavior of silver nanoparticle agglomerates and effects of the agglomerate model in data analysis. J Nanopart Res 15:1709. doi:10. 1007/s11051-013-1709-z

Chen DR, Pui DYH, Hummes D, Fissan H, Quant FR, Sem GJ (1998) Design and evaluation of a nanometer aerosol differential mobility analyzer (Nano-DMA). J Aerosol Sci 29:497-509

Chen S-C, Wang J, Fissan F, Pui DYH (2013a) Use of Nuclepore filters for ambient and workplace nanoparticle exposure assessment-spherical particles. Atmos Environ 77:385-393

Chen S-C, Wang J, Fissan F, Pui DYH (2013b) Exposure assessment of nanosized engineered agglomerates and 
aggregates using Nuclepore filter. J Nanopart Res 15:1955. doi:10.1007/s11051-013-1955-0

Cheng Y-S, Chen BT (1995) Aerosol sampler calibration, in air sampling instruments, 5th edn. ACGIH, Cincinnati

Cheng YS, Yeh HC (1980) Theory of a screen-type diffusion battery. J Aerosol Sci 11:313-320

Cyrs WD, Boysen DA, Casuccio G, Lersch T, Peters TM (2010) Nanoparticle collection efficiency of capillary pore membrane filters. J Aerosol Sci 41:655-664

Davies CN (ed) (1973) Air filtration. Academic Press, London

Donaldson K, Li XY, MacNee W (1998) Ultrafine (nanometer) particle mediated lung injury. J Aerosol Sci 29:553-560

Eninger RM, Honda T, Adhikari A, Tanski H, Reponen T, Grinshpun SA (2008a) Filter performance of N99 and N95 facepiece respirators against viruses and ultrafine particles. Ann Occup Hyg 52:385-396

Eninger RM, Takeshi H, Reponen T, McKay R, Grinshpun SA (2008b) What does respirator certification tell us about filtration of ultrafine particles? J Occup Environ Hyg 5:286-295

Eshbaugh JP, Gardner PD, Richardson AW (2009) N95 and P100 respirator filter efficiency under high constant and cyclic flow. J Occup Environ Hyg 6:52-61. doi:10.1080/ 15459620802558196

European Committee for Standardization (2000) EN 143:2000 "Respiratory protective devices-particle filtersrequirements, testing, marking". CEN, Brussels

European Committee for Standardization (2009a) EN 1822-1:2009 "High efficiency air filters (EPA, HEPA and ULPA)_part 1: classification, performance testing, marking". CEN, Brussels

European Committee for Standardization (2009b) EN 1822-2:2009 "High efficiency air filters (EPA, HEPA and ULPA) - part 2: aerosol production, measuring equipment, particle counting statistics". CEN, Brussels

European Committee for Standardization (2009c) EN 1822-3:2009 "High efficiency air filters (EPA, HEPA and ULPA) - part 3: testing flat sheet filter media". CEN, Brussels

European Committee for Standardization (2009d) EN 1822-4:2009 "High efficiency air filters (EPA, HEPA and ULPA) - part 4: determining leakage of filter elements (scan method)". CEN, Brussels

European Committee for Standardization (2009e) EN 1822-5:2009 "High efficiency air filters (EPA, HEPA and ULPA)—part 5: determining the efficiency of filter elements". CEN, Brussels

European Committee for Standardization (2012) EN 779:2012 "Particulate air filters for general ventilation-determination of the filtration performance". CEN, Brussels

Fernandez de la Mora JF, Labowsky M, Schmitt III J, Nelson W (2004) Method and apparatus to increase the resolution and widen the range of differential mobility analyzers (DMA's), United States. US 6,787,763

Flagan RC (2008) Differential mobility analysis of aerosols: a tutorial. KONA Powder Part J 26:254-268

Furuuchi M, Eryu K, Nagura M, Hata M, Kato T, Tajima N, Sekiguchi K, Ehara K, Seto T, Otani Y (2010) Development and performance evaluation of air sampler with inertial filter for nanoparticle sampling. Aerosol Air Qual Res 10:185-192
Golanski L, Guiot A, Rouillon F, Pocachard J, Tardif F (2009) Experimental evaluation of personal protection devices against graphite nanoaerosols: fibrous filter media, masks, protective clothing, and gloves. Hum Exp Toxicol 28:353-359

Heim M, Mullins BJ, Wild M, Meyer J, Kasper G (2005) Filtration efficiency of aerosol particles below 20 nanometers. Aerosol Sci Technol 39:782

Heim M, Mullins BJ, Kasper G (2006) Comment on: penetration of ultrafine particles and ion clusters through wire screens by Ichitsubo et al. Aerosol Sci Technol 40:144-145

Heim M, Attoui M, Kasper G (2010) The efficiency of diffusional particle collection onto wire grids in the mobility equivalent size range of $1.2-8 \mathrm{~nm}$. J Aerosol Sci 41:207

Hinds WC (1999) Aerosol technology: properties, behavior, and measurement of airborne particles, 2nd edn. Wiley-Interscience, New York

Huang S-H, Chen C-W, Chang C-P, Lai C-Y, Chen C-C (2007) Penetration of $4.5 \mathrm{~nm}$ to $10 \mu \mathrm{m}$ aerosol particles through fibrous filters. J Aerosol Sci 38:719

Ichitsubo H, Hashimoto T, Alonso M, Kousaka Y (1996) Penetration of ultrafine particles and ion clusters through wire screens. Aerosol Sci Technol 24:119

Iida K, Stolzenburg MR, McMurry PH (2009) Effect of working fluid on sub- $2 \mathrm{~nm}$ particle detection with a laminar flow ultrafine condensation particle counter. Aerosol Sci Technol 43:81-96

International Organization for Standardization (2011a) ISO 29463-1:2011 "High-efficiency filters and filter media for removing particles in air-part 1: classification, performance testing and marking". ISO, Geneva

International Organization for Standardization (2011b) ISO 29463-2:2011 "High-efficiency filters and filter media for removing particles in air-part 2: aerosol production, measuring equipment and particle-counting statistics". ISO, Geneva

International Organization for Standardization (2011c) ISO 29463-3:2011 "High-efficiency filters and filter media for removing particles in air-part 3: testing flat sheet filter media". ISO, Geneva

International Organization for Standardization (2011d) ISO 29463-4:2011 "High-efficiency filters and filter media for removing particles in air-part 4: test method for determining leakage of filter elements-Scan method". ISO, Geneva

International Organization for Standardization (2011e) ISO 29463-5:2011 "High-efficiency filters and filter media for removing particles in air-part 5: test method for filter elements". ISO, Geneva

International Organization for Standardization (2013) ISO 29461-1:2013 "Air intake filter systems for rotary machinery—test methods-part 1: static filter elements". ISO, Geneva

Japuntich D, Franklin L, Pui D, Kuehn T, Kim SC, Viner AS (2007) A comparison of two nano-sized particle air filtration tests in the diameter range of 10 to 400 nanometers. J Nanopart Res 9:93-107

Kim CS, Bao L, Okuyama K, Shimada M, Niinuma H (2006) Filtration efficiency of a fibrous filter for nanoparticles. J Nanopart Res 8:215-221 
Kim SC, Harrington MS, Pui DYH (2007) Experimental study of nanoparticles penetration through commercial filter media. J Nanopart Res 9:117-125

Kim SC, Wang J, Emery M, Shin WG, Mulholland G, Pui DYH (2009) Structural property effect of nanoparticle agglomerates on particle penetration through fibrous filter. Aerosol Sci Technol 43:344-355. doi:10.1080/02786820802653763

Kirsch AA, Fuchs NA (1968) Studies of fibrous filters-III: diffusion deposition of aerosols in fibrous filters. Ann Occup Hyp 11:299-304

Kraemer HF, Johnstone HF (1955) Collection of aerosol particles in presence of electrostatic fields. Ind Eng Chem 47(12):2426-2434

Lathrache R, Fissan H (1989) Grundlegende Untersuchungen zum Abscheideverhalten der Elektret-Filter Teil 1: Bestimmung der Abscheidegrade. Staub Reinhalt Luft 49:309-314

Lee KW, Liu BYH (1980) On the minimum efficiency and the most penetrating particle size for fibrous filters. J Air Pollut Control Assoc 30:377-381

Lee KW, Liu BYH (1982) Theoretical study of aerosol filtration by fibrous filters. Aerosol Sci Technol 1:147-161

Lee KW, Mukund R (2001) Filtration collection. In: Baron PA, Willeke K (eds) Aerosol measurement-principles, techniques, and application, 2nd edn. Wiley, Hoboken

Lee S-A, Grinshpun SA, Reponen T (2008) Respiratory performance offered by $\mathrm{N} 95$ respirators and surgical masks: human subject evaluation with $\mathrm{NaCl}$ aerosol representing bacterial and viral particle size range. Ann Occup Hyg 52:177-185. doi:10.1093/annhyg/men005

Liu BYH, Pui DYH (1974) A submicron aerosol standard and the primary absolute calibration of the condensation nuclei counter. J Colloid Interface Sci 47:155-171

Liu BYH, Romay FJ, Dick WD, Woo K-S, Chiruta M (2010) A wide-range particle spectrometer for aerosol measurement from $0.010 \mu \mathrm{m}$ to $10 \mu \mathrm{m}$. Aerosol Air Qual Res 10:125-139

Liu J, Pui DYH, Wang J (2011) Removal of airborne nanoparticles by membrane coated filters. Sci Total Environ 409:4868-4874

Liu Z, Kim SC, Wang J, Fissan H, Shin WG, Pui DYH (2012) Measurement of metal nanoparticle agglomerates generated by spark discharge using the universal nanoparticle analyzer (UNPA). Aerosol Sci Technol 46(3):333-346

Lore MB, Sambol AR, Japuntich DA, Franklin LM, Hinrichs SH (2011) Inter-laboratory performance between two nanoparticle air filtration systems using scanning mobility particle analyzers. J Nanopart Res 13:1581-1591

Manton MJ (1978) The impaction of aerosols on a Nuclepore filter. Atmos Environ 12:1669-1675

Manton MJ (1979) Brownian diffusion of aerosols to the face of a Nuclepore filter. Atmos Environ 13:525-531

Marre S, Palmeri J (2001) Theoretical study of aerosol filtration by nucleopore filters: the intermediate crossover regime of Brownian diffusion and direct interception. J Colloid Interface Sci 237:230-238

Martin SB Jr, Moyer ES (2000) Electrostatic respirator filter media: filter efficiency and most penetrating particle size effects. Appl Occup Environ Hyg 15:609-617. doi:10. 1080/10473220050075617
Maynard AD, Pui DYH (2007) Nanoparticles and occupational health, Springer, p 186. ISBN-10-1-4020-5858-6

Mostofi R, Wang B, Haghighat F, Bahloul A, Jaime L (2010) Performance of mechanical filters and respirators for capturing nanoparticles-limitations and future direction. Ind Health 48:296-304

Mouret G, Chazelet S, Thomas D, Bemer D (2011) Discussion about the thermal rebound of nanoparticles. Sep Purif Technol 78:125

Natanson GL (1957) Deposition of aerosol particles by electrostatic attraction upon a cylinder around which they are flowing. Dokl Akad Nauk USSR 112:696-699 (in Russian); HSE Translation 7222 (1977)

NIOSH (1995) Respiratory protective devices; final rule and notices. Fed Regist 60(110):30335-30404

Oberdörster G, Gelein RM, Ferin J, Weiss B (1995) Association of particulate air pollution and acute mortality: involvement of ultrafine particles. Inhalation Toxicol 7:111-124

Oberdörster G, Oberdörster E, Oberdörster J (2005) Nanotoxicology: an emerging discipline evolving from studies of ultrafine particles. Environ Health Perspect 113:823-839

Otani Y, Emi H, Mori J (1993) Initial collection efficiency of electret filter and its durability for solid and liquid particles. KONA Powder Part J 11:207

Otani Y, Emi H, Cho S-J, Namiki N (1995) Generation of nanometer size particles and their removal from air. Adv Powder Technol 6:271

Otani Y, Eryu K, Furuuchi M, Tajima N, Tekasakul P (2007) Inertial classification of nanoparticles with fibrous filters. Aerosol Air Qual Res 7:343

Pich J (1964) Impaction of aerosol particles in the neighborhood of a circular hole. Collect Czech Chem Commun 29:2223-2227

Pich J, Emi H, Kanaoka C (1987) Coulombic mechanism in electret filters. J Aerosol Sci 18(1):29-35

Pourprix M, Daval J (1990) Electrostatic precipitation of aerosols on wafers, a new mobility spectrometer. In: Masuda S, Takahashi K (eds) Aerosols: science, industry, health and environment, vol 2. Pergamon Press, New York

Rengasamy A, Verbofsky R, King WP, Shaffer RE (2007) Nanoparticle penetration through NIOSH-approved N95 filtering-facepiece respirators. J Int Soc Res Prot 24:49-59

Rengasamy S, King WP, Eimer BC, Shaffer RE (2008) Filtration performance of NIOSH-approved N95 and P100 filtering facepiece respirators against 4 to 30 nanometer-size nanoparticles. J Occup Environ Hyg 5:556-564

Rengasamy S, Eimer BC, Shaffer R (2009) Comparison of nanoparticle filtration performance of NIOSH-approved and CE-marked particulate filtering facepiece respirators. Ann Occup Hyg 53(2):117-128

Richardson AW, Eshbaugh JP, Hofacre KC, Gardner PD (2006) Respirator filter efficiency testing against particulate and biological aerosols under moderate to high flow rates. U.S. Army Edgewood Chemical Biological Center Report for Contract No. SP0700-00-D-3180, Task No. 335, ECBCCR-085. http://www.cdc.gov/niosh/npptl/researchprojects/ pdfs/CR-085Gardner.pdf. Accessed 20 July 2008

Rosser S, Fernandez de la Mora J (2003) A short Vienna-type DMA of high resolution and high flow rate. J Aerosol Sci 2003:S917-S918 
Rubow KL (1981) Submicrometer aerosol filtration characteristics of membrane filters. Ph.D. thesis, University of Minnesota

Rubow KL, Liu BYH (1986) Characteristics of membrane filters for particle collection. In: Raber RR (ed) Fluid filtration: gas, vol I, ASTM STP 975. American Society for Testing and Materials, Philadelphia

Russell LM, Flagan RC, Seinfeld JH (1995) Asymmetric instrument response resulting from mixing effects in accelerated DMA-CPC measurements. Aerosol Sci Technol 23:491-509

Schwyn S, Garwin E, Schmidt-Ott A (1988) Aerosol generation by spark discharge. J Aerosol Sci 19(5):639-642

Seto T, Furukawa T, Otani Y, Uchida K, Endo S (2010) Filtration of multi-walled carbon nanotube aerosol by fibrous filters. Aerosol Sci Technol 44:734-740

Sgro LA, Fernandez de la Mora J (2004) A simple turbulent mixing $\mathrm{CNC}$ for charged particle detection down to $1.2 \mathrm{~nm}$. Aerosol Sci Technol 38:1-11

Shaffer RE, Rengasamy S (2009) Respiratory protection against airborne nanoparticles: a review. J Nanopart Res $11: 1661-1672$

Shin WG, Mulholland GW, Kim SC, Pui DYH (2008) Experimental study of filtration efficiency of nanoparticles below $20 \mathrm{~nm}$ at elevated temperatures. J Aerosol Sci 39:488-499

Spurny KR, Lodge JP, Frank ER, Sheesley DC (1969) Aerosol filtration by means of Nuclepore filters: structural and filtration properties. Environ Sci Technol 3:453-464

Stanley N, Qi C, Pui DYH (2010) A new method of filter efficiency evaluation using the nanoparticle surface area monitor (NSAM) for a nanoparticle health relevant filter efficiency measure. Filtration 10(1):40-46

Stechkina IB (1966) Diffusion precipitation of aerosols in fiber filters. Dokl Acad Nauk SSSR 167(6):1327

Stechkina IB, Kirsch AA, Fuchs NA (1969) Studies on fibrous aerosol filters-IV. Calculation of aerosol deposition in model filters in the region of maximum penetration. Ann Occ Hyg 12:1-8

Steffens J, Coury JR (2007a) Collection efficiency of fiber filters operating on the removal of nano-sized aerosol particles: I-homogeneous fibers. Sep Purif Technol 58:99-105

Steffens J, Coury JR (2007b) Collection efficiency of fiber filters operating on the removal of nano-sized aerosol particles II. Heterogeneous fibers. Sep Purif Technol 58:106-112

Stenhouse JIT (1974) The influence of electrostatic forces in fibrous filtration. Filtr Sep 11:25-26

Thomas D, Mouret G, Cadavid-Rodriguez MC, Chazelet S, Bemer D (2013) An improved model for the penetration of charged and neutral aerosols in the 4 to $80 \mathrm{~nm}$ range through stainless steel and dielectric meshes. J Aerosol Sci 57:32-44

Tronville P, Rivers RD (2005a) International standards: filters for buildings and gas turbines. Filtr Sep 42(7):39-43

Tronville P, Rivers RD (2005b) International standards: filters for vehicular applications. Filtr Sep 42(9):24-27

Tronville P, Rivers RD (2006) Global standards for filter testing. ASHRAE J 48(8):58-62

TSI (2008) Model 8127/8130 automated filter tester operation and service manual, TSI Inc, Shoreview, MN, USA
Twomey S (1962) Equations for the decay of diffusion of particles in an aerosol flowing through circular or rectangular channels. Bull Observ Puy de Dome 10:173-180

Vanhanen J, Mikkilä J, Lehtipalo K, Sipilä M, Manninen HE, Siivola E, Petäjä T, Kulmala M (2011) Particle size magnifier for nano-CN detection. Aerosol Sci Technol 45:533-542

Vo E, Zhuang Z (2013) Development of a new test system to determine penetration of multi-walled carbon nanotubes through filtering facepiece respirators. J Aerosol Sci 61:50-59

Wang J (2013) Effects of particle size and morphology on filtration of airborne nanoparticles. KONA Powder Part J 30:256-266

Wang SC, Flagan RC (1990) Scanning electrical mobility spectrometer. Aerosol Sci Technol 13:230-240

Wang C-S, Otani Y (2013) Removal of nanoparticles from gas streams by fibrous filters: a review. Ind Eng Chem Res 52:5-17

Wang J, Pui DYH (2009) Filtration of aerosol particles by elliptical fibers: a numerical study. J Nanopart Res 11:185-196

Wang J, Chen DR, Pui DYH (2007) Modeling of filtration efficiency of nanoparticles in standard filter media. J Nanopart Res 9:109-115

Wang J, Kim SC, Pui DYH (2008a) Figure of merit of composite filters with micrometer and nanometer fibers. Aerosol Sci Technol 42:722-728. doi:10.1080/02786820802249133

Wang J, Kim SC, Pui DYH (2008b) Investigation of the figure of merit for filters with a single nanofiber layer on a substrate. J Aerosol Sci 39:323-334. doi:10.1016/j.jaerosci.2007.12.003

Wang J, Kim SC, Pui DYH (2011a) Carbon nanotube penetration through a screen filter: numerical modeling and comparison with experiments. Aerosol Sci Technol 45:443-452. doi:10.1080/02786826.2010.541531

Wang J, Kim SC, Pui DYH (2011b) Measurement of multi-wall carbon nanotube penetration through a screen filter and single-fiber analysis. J Nanopart Res 13(10):4565-4573. doi:10.1007/s11051-011-0415-y

Winkelmayr W, Reischl GP, Linder AO, Berner A (1991) A new electromobility spectrometer for the measurement of aerosol size distribution in the size range from 1 to $1000 \mathrm{~nm}$. J Aerosol Sci 22:289-296

Yang S, Lee GWM (2005) Filtration characteristics of a fibrous filter pretreated with anionic surfactants for monodisperse solid aerosols. J Aerosol Sci 36:419-437

Yook SJ, Fissan H, Engelke T, Asbach C, van der Zwaag T, Kim JH, Wang J, Pui DYH (2008) Classification of highly monodisperse nanoparticles of NIST-traceable sizes by TDMA and control of deposition spot size on a surface by electrophoresis. J Aerosol Sci 39:537-548

Zaviska F (1951) Kinetic theory of gases. Akademicke, Prague

Zhang SH, Akutsu Y, Russell LM, Flagan RC, Seinfeld JH (1995) Radial differential mobility analyzer. Aerosol Sci Technol 23:357-372 